

\section{A}

\section{Enfoque y alcance}

La Revista de Arquitectura (ISSN 1657-0308 Impresa y E-ISSN 2357-626X en línea) es una publicación seriada de acceso abierto, arbitrada mediante revisión por pares (doble ciego) e indexada, en donde se publican resultados de investigación originales e inéditos.

Está dirigida a la comunidad académica y profesional de las áreas afines a la disciplina. Es editada por la Facultad de Diseño y el Centro de Investigaciones (CIFAR) de la Universidad Católica de Colombia en Bogotá (Colombia).

La principal área científica a la que se adscribe la Revista de Arquitectura según la OCDE es:

Gran área: 6. Humanidades

Área: 6.D. Arte

Disciplina: 6D07. Arquitectura y Urbanismo

También se publican artículos de las disciplinas como 2A02, Ingeniería arquitectónica; 5G03, Estudios urbanos (planificación y desarrollo); 6D07, Diseño.

Los objetivos de la Revista de Arquitectura son:

- Promover la divulgación y difusión del conocimiento generado a nivel local, nacional e internacional

- Conformar un espacio para la construcción de comunidades académicas y la discusión en torno a las secciones definidas.

- Fomentar la diversidad institucional y geográfica de los autores que participan en la publicación.

- Potenciar la discusión de experiencias e intercambios científicos entre investigadores y profesionales.

- Contribuir a la visión integral de la arquitectura, por medio de la concurrencia y articulación de las secciones mediante la publicación de artículos de calidad.

- Publicar artículos originales e inéditos que han pasado por revisión de pares, para asegurar que se cumplen las normas éticas, de calidad, validez científica, editorial e investigativa.

- Fomentar la divulgación de las investigaciones y actividades desarrolladas en la Universidad Católica de Colombia.
Palabras clave de la Revista de Arquitectura: arquitectura, diseño, educación arquitectónica, proyecto y construcción, urbanismo.

Idiomas de publicación: español, inglés, portugués y francés.

Título abreviado: Rev. Arquit.

Titulo corto: RevArq

\section{Políticas de sección}

La revista se estructura en tres secciones correspondientes a las líneas de investigación activas y aprobadas por la institución, y dos complementarias, que presentan dinámicas propias de la Facultad de Diseño y las publicaciones relacionadas con la disciplina.

CULTURA Y ESPACIO URBANO. En esta sección se publican los artículos que se refieren a fenómenos sociales en relación con el espacio urbano, atendiendo aspectos de la historia, el patrimonio cultural y físico, y la estructura formal de las ciudades y el territorio.

Proyecto ARQUitectónico y URBANO. En esta sección se presentan artículos sobre el concepto de proyecto, entendido como elemento que define y orienta las condiciones proyectuales que devienen en los hechos arquitectónicos o urbanos, y la forma como estos se convierten en un proceso de investigación y nuevo de conocimiento. También se presentan proyectos que sean resultados de investigación, los cuales se validan por medio de la ejecución y transformación en obra construida del proceso investigativo. También se contempla la publicación de investigaciones relacionadas con la pedagogía y didáctica de la arquitectura, el urbanismo y el diseño.

TECNOLOGÍA, MEDIOAMBIENTE Y SOSTENIBILIDAD. En esta sección se presentan artículos acerca de sistemas estructurales, materiales y procesos constructivos, medioambiente y gestión, relacionados con los entornos social-cultural, ecológico y económico.

DESDE LA FACULTAD. En esta sección se publican artículos generados en la Facultad de Diseño, relacionados con las actividades de docencia, extensión, formación en investigación o internacionalización, las cuales son reflejo de la dinámica y de las actividades realizadas por docentes, estudiantes y egresados; esta sección no puede superar el $20 \%$ del contenido.

TExTos. En esta sección se publican reseñas, traducciones y memorias de eventos relacionados con las publicaciones en Arquitectura y Urbanismo.

\section{A FRECUENCIA DE PUBLICACIÓN}

Desde 1999 y hasta el 2015, la Revista de Arquitectura publicó un volumen al año, a partir del 2016 se publicarán dos números por año en periodo anticipado, enero-junio y julio-diciembre, pero también maneja la publicación anticipada en línea de los artículos aceptados (versión Post-print del autor).

La Revista de Arquitectura se divulga mediante versiones digitales (PDF, HTML, XML) e impresas con un tiraje de 700 ejemplares, los tiempos de producción de estas versiones dependerán de los cronogramas establecidos por la editorial.

Los tiempos de recepción-revisión-aceptación pueden tardar entre seis y doce meses dependiendo del flujo editorial de cada sección y del proceso de revisión y edición adelantado.

Con el usuario y contraseña asignados, los autores pueden ingresar a la plataforma de gestión editorial y verificar el estado de revisión, edición o publicación del artículo.

\section{A CANJE}

La Revista de Arquitectura está interesada en establecer canje con publicaciones académicas, profesionales o científicas del área de Arquitectura y Urbanismo, como medio de reconocimiento y discusión de la producción científica en el campo de acción de la publicación.

\section{Mecanismo}

Para establecer canje por favor descargar, diligenciar y enviar el formato: RevArq FP20 Canjes

http://publicaciones.ucatolica.edu.co/revista/ arquitectura/RevArq_FP20_Canje_V2.doc

Universidad Católica de Colombia (2016, enero-junio). Revista de Arquitectura, 18(1), $1-144$.

ISSN: 1657-0308 E-ISSN: 2357-626X

Especificaciones:

Formato: $34 \times 24 \mathrm{~cm}$

Papel: Mate $115 \mathrm{~g}$

Tintas: Negro y policromía

\section{A CONTACTO}

DIRECCIÓN POSTAL:

Avenida Caracas No. 46-72. Universidad Católica de

Colombia. Bogotá D.C.(Colombia)

Código postal: 111311

Facultad de Diseño, Centro de Investigaciones (CIFAR). Sede El Claustro. Bloque "L", 4 piso, Diag. 46를. No. 15b-10. Editor, Arq. César Andrés Eligio Triana

Teléfonos: +57 (1) 3277300 - 3277333

Ext. $3109 ; 3112$ o 5146

Fax: +57 (1) 2858895

CORREO ELECTRÓNICO:

revistadearquitectura@ucatolica.edu.co cifar@ucatolica.edu.co

PÁGINA WEB:

www.ucatolica.edu.co vínculo Revistas científicas http://publicaciones.ucatolica.edu.co/revistas-cientificas http://editorial.ucatolica.edu.co/ojsucatolica/revistas_ucatolica/index.php/RevArq 
UNIVERSIDAD CATÓLICA DE COLOMBIA

PRESIDENTE

Édgar Gómez Betancourt

VICEPRESIDENTE - RECTOR

Francisco José Gómez Ortiz

VICERRECTOR JURÍDICO Y DEL MEDIO

UNIVERSITARIO

Edwin de Jesús Horta Vásquez

VICERRECTOR ADMINISTRATIVO

Édgar Gómez Ortiz

DECANO ACADÉMICO

Elvers Medellín Lozano

DIRECTORA DE INVESTIGACIONES

Elisa Urbina Sánchez

DIRECTORA EDITORIAL

Stella Valbuena García

\section{FACULTAD DE DISEÑO}

DECANO

Werner Gómez Benítez

DIRECTOR DE DOCENCIA

Jorge Gutiérrez Martínez

DIRECTOR DE EXTENSIÓN

Adriana Pedraza Pacheco

DIRECTOR DE INVESTIGACIÓN

Hernando Verdugo Reyes

DIRECTOR DE GESTIÓN DE CALIDAD

Augusto Forero La Rotta

COMITÉ ASESOR EXTERNO

FACUlTAD DE DisEÑo

Alberto Miani Uribe

Giovanni Ferroni Del Valle

Samuel Ricardo Vélez

Lorenzo Castro

FACULTAD DE DISEÑO

REVISTA DE ACCESO ABIERTO,

ARBITRADA E INDEXADA

Publindex Categoría B. Índice Bibliográfico Nacional

IBN. Colombia.

Redalyc. Red de Revistas Científicas de América Latina

y el Caribe, España y Portugal. Sistema de Información

Científica. México.

Proquest. ProQuest Research LibraryProQuest

Research Library ProQuest Research Library. Estados

Unidos

Ebsco. EBSCOhost Research Databases. Estados

Unidos.

Latindex. Sistema Regional de Información en Línea

para Revistas Científicas de América Latina, el Caribe,

España y Portugal (Directorio y catálogo). México.

Clase. Base de datos bibliográfica de revistas de cien-

cias sociales y humanidades. Universidad Autónoma

México.

Dialnet. Fundación Dialnet - Biblioteca de la Universi-

dad de La Rioja. España.

Actualidad Iberoamericana. (Índice de Revistas) Centro de Información Tecnológica (CIT). Chile.

Arla. Asociación de revistas latinoamericanas de arquitectura.

EDITORIAL

Av. Caracas No 46-72, piso 5

Teléfono: 3277300 Ext. 5145

editorial@ucatolica.edu.co

www.ucatolica.edu.co

http://publicaciones.ucatolica.edu.co/

IMPRESIÓN:

ESCALA Taller Litográfico

Calle 30 № 17-52 - (057 I) 2320482

Abril de 2016

\section{REVISTA DE ARQUITECTURA}

DIRECTOR

Werner Gómez Benítez

EDITOR

César Andrés Eligio Triana

EDITOR DE SECCIÓN

Carolina Rodríguez Ahumada

CONSEJO EDITORIAL

Werner Gómez Benítez

Jorge Gutiérrez Martínez

César Andrés Eligio Triana

Hernando Verdugo Reyes

\section{EQUIPO EDITORIAL}

COORDINADORA EDITORIAL

María Paula Godoy Casasbuenas mpgodoy@ucatolica.edu.co

DiseÑo Y MONTAJE

Juanita Isaza

juanaisaza@gmail.com

TRADUCTORES

INGLÉS

Massayel Cuéllar Hernández

massacuellar@gmail.com

CORRECTORA DE ESTILO

María José Díaz Granados M.

mariajose_dgm@yahoo.com.co

PÁGINA WEB

Centro de investigaciones (CIFAR)

DISTRIBUCIÓN Y CANJES

Claudia Álvarez Duquino

calvarez@ucatolica.edu.co
COMITÉ EDITORIAL Y CIENTÍFICO Cultura Y ESPACIO URBANO

Carlos Mario Yory, PhD

Universidad Católica de Colombia. Bogotá, Colombia

Sonia Berjman, $\mathrm{PhD}$

ICOMOS-IFLA, Buenos Aires, Argentina

Juan Carlos Pérgolis, MSc Universidad Piloto de Colombia. Bogotá, Colombia

Beatriz García Moreno, PhD

Universidad Nacional de Colombia. Bogotá, Colombia

Javier Peinado Pontón, Msc

Pontificia Universidad Javeriana. Bogotá, Colombia

Proyecto arquitectónico y URBano

Jean-Philippe Garric, PhD, HDR

Université Paris I Panthéon-Sorbonne. Paris, Francia

Debora Domingo Calabuig, $\mathrm{PhD}$

Universidad Politécnica de Valencia, España

Hugo Mondragón López, PhD

Pontificia Universidad Católica de Chile. Santiago, Chile

Germán Darío Correal Pachón, MSc Universidad Católica de Colombia. Bogotá, Colombia

Juan Pablo Duque Cañas, PhD

Universidad Nacional de Colombia. Bogotá, Colombia

Jorge Grané del Castillo, MSc Universidad de Costa Rica. San José, Costa Rica

\section{TECNOLOGÍA, MEDIOAMBIENTE Y SOSTENIBILIDAD}

Mariano Vázquez Espí, PhD.

Universidad Politéencica de Madrid, España.

Luis Carlos Herrera Sosa, PhD

Universidad Autónoma de Ciudad Juárez, México

Claudio Varini, PhD

Universidad Católica de Colombia. Bogotá, Colombia

Luis Gabriel Gómez Azpeitia, PhD Universidad de Colima. Colima, México 


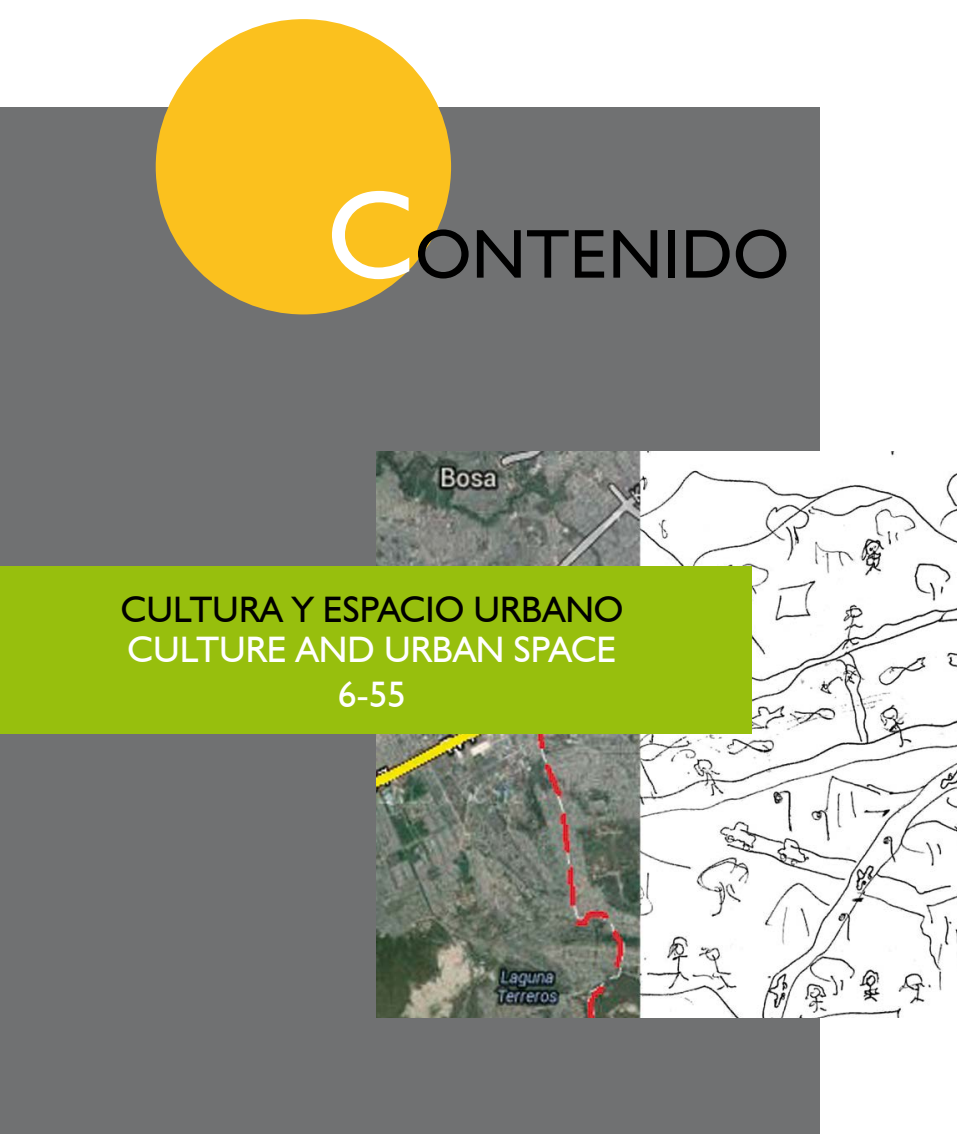

URBANISMO PARTICIPATIVO

CONSTRUCCIÓN SOCIAL DEL ESPACIO URBANO

MARY JOHANA HERNÁNDEZ ARAQUE

LA REPRESENTACIÓN SOCIAL DEL ESPACIO PÚBLICO PARA EL DISEÑO Y LA GESTIÓN DE TERRITORIOS SOSTENIBLES

UNA PROPUESTA TEÓRICO-PRÁCTICA Y METODOLÓGICA PARA UN URBANISMO PARTICIPATIVO

HeIDI NATALIE CONTRERAS-LOVICH

PROPUESTA DE UN SISTEMA DE INDICADORES PARA EVALUAR LA CALIDAD VISUAL DEL PAISAJE URBANO EN ASENTAMIENTOS INFORMALES

JOHANA ANDREA MESA CARRANZA, OSWALDO LÓPEZ BERNAL, ADRIANA PATRICIA LÓPEZ VALENCIA

\section{SEGREGACIÓN EN EL ESPACIO URBANO DE SOACHA}

¿TRANSMILENIO COMO HERRAMIENTA INTEGRADORA?

CARLOS AUGUSTO MORENO-LUNA

ARQUITETURA E INDUSTRIALIZAÇÃO DAS

CONSTRUÇÕES NA OBRA DE JOÃO FILGUEIRAS

LIMA - LELE

ELZA-LULI MIYASAKA, MARIELI LUKIANTCHUKI,

Michele C. B. Ferrari CaiXeta, Marcio-Minto Fabrício PÁg. 56

EL DISEÑO DE LA VIVIENDA DE INTERÉS SOCIAL

LA SATISFACCIÓN DE LAS NECESIDADES Y EXPECTATIVAS DEL USUARIO

ALEX LEANDRo PÉREZ-PÉREZ

\section{EXPLORACIONES MORFOLÓGICAS EN TEXTURAS} MODULARES

APROXIMACIONES DESDE EL OBIET TROUVÉ

AL DISEÑO PARAMÉTRICO

OMAR CAÑETE-ISLAS

TECNOLOGÍA, MEDIOAMBIENTE Y SOSTENIBILIDAD

TECHINOLOGY, ENVIRONMENT AND SUSTAINABILITY $76-125$
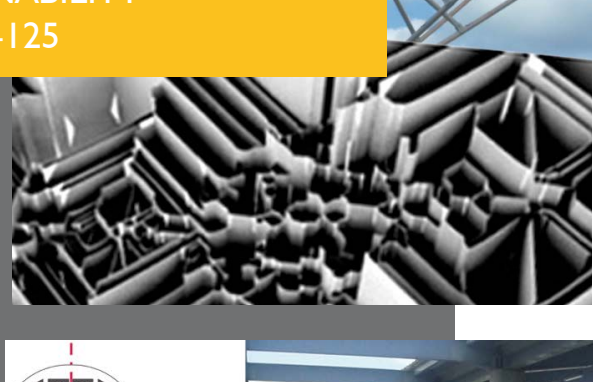

DESDE LA FACULTAD

FROM THE FACULTY 126-139

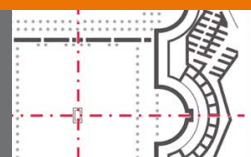

TEXTOS

TEXTS

I40-142
CONSTRUCCIÓN EXPERIMENTAL DE UN SISTEMA TRANSFORMABLE TENSADO PLEGABLE

CARLOS CÉSAR MORALES GUZMÁN

\section{LA SIMULACIÓN COMO HERRAMIENTA DE} DISEÑO Y EVALUACIÓN ARQUITECTÓNICA

PAUTAS RESUELTAS DESDE LA INGENIERÍA

JOHANNA TRUJILLO, ROLANDO ARTURO CUBILLOS-GONZÁLEZ

LAS RELACIONES ENTRE LA MOVILIDAD

Y EL ESPACIO PÚBLICO

TRANSMILENIO EN BOGOTÁ

Myriam STELLA Díaz-OSORIO, JuLIO CÉSAR MARRoQuíN

APRENDIZAJE, COMPOSICIÓN Y EMPLAZAMIENTO EN EL PROYECTO DE ARQUITECTURA [REVISIÓN DE LIBRO]

JUAN CARLOS PÉRGOLIS

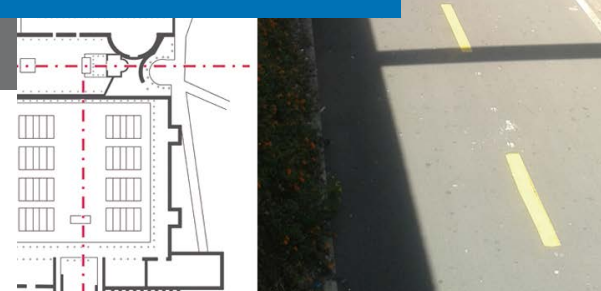




\title{
CONSTRUCCIÓN EXPERIMENTAL DE UN SISTEMA TRANSFORMABLE TENSADO PLEGABLE
}

\author{
Carlos César Morales Guzmán \\ Universidad Veracruzana, Ciudad Poza Rica, Veracruz (México) \\ Facultad de Arquitectura, Región Poza Rica (FAUV)
}

\section{Morales Guzmán, C. C. (2016). Cons- trucción experimental de un sistema transformable tensa- do plegable. Revista de Arqui- tectura, I8(I), 98-II0. doi: 10.14718/RevArq.2016.18.1.9

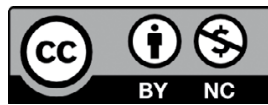

http://dx.doi.org/10.14718/RevArg.2016.18.1.9
Arquitecto, Universidad Veracruzana.

Maestro en Arquitectura, Universidad Cristóbal Colón. Magíster en Ingeniería Estructural, Universidad Camilo José Cela. Doctor en Arquitectura, Universidad Nacional Autónoma de México. Posdoctorado en Arquitectura Tensada, Universidad Politécnica de Catalunya.

Posdoctorado en Arquitectura e Ingeniería Transformable, Universidad Politécnica de Catalunya.

Investigador-Académico de tiempo completo, Titular C, Universidad Veracruzana, Facultad de Arquitectura, región Poza Rica, Tuxpan.

Perfil deseable PROMEP (20I2), Miembro del Sistema Nacional Investigación, CONACyT, en la Modalidad de Candidato (20I3).

Publicaciones recientes:

(20I3). Prototipo de diseño de una cubierta retráctil tensada. Revista de Arquitectura, I5(1), 102-1 I0.

(20I2). Diseño de sistemas flexibles para la arquitectura. Madrid: Editorial Academia Española.

(20I2). Diseño de sistemas versátiles en los sistemas orgánicos. Revista Esencia y Espacio, 34-35.

(20II). Diseño de una vivienda bioclimática industrial. Revista Bitá cora, 24

carlmorales@uv.mx

\section{RESUMEN}

El objetivo de esta investigación es el desarrollo de un modelo experimental con el fin de estudiar las características de los sistemas retráctiles. El modelo experimental consistió en la construcción de un paraguas retráctil de 4 miembros. Luego se mejoró el modelo experimental al agregarle 8 miembros, con el objeto de mantener un mejor equilibrio estructural. El diseño del modelo está sustentado por el código europeo EHE08, pero se rediseñó con el código de LRFD para tener un diámetro acorde a los requerimientos locales. Además, el modelo ayudó a formar conceptos constructivos del movimiento de los sistemas plegables en forma de paraguas, lo que dio como resultado un sistema plegable retráctil, el cual se inclinó sobre la construcción de un nodo para unir dos elementos creando un sistema estructural resistente. Con este trabajo se concluyó que los sistemas transformables pueden ayudar a mejorar los diseños de sistemas estructurales flexibles.

PALABRAS CLAVE: diseño estructural, detalles constructivos, investigación y desarrollo, sistema plegable retráctil, simulación estructural.

\section{EXPERIMENTAL CONSTRUCTION OF A TRANSFORMABLE FOLDING}

TENSIONING SYSTEM

\section{ABSTRACT}

The objective of this research is to develop an experimental model to study the characteristics of retractable systems. The experimental model involved the construction of a 4 limbs retractable umbrella. The experimental model by adding 8 members, in order to maintain better structural balance is then improved. The design model is supported by the European code EHE08, but was redesigned with LRFD code to have a diameter according to local requirements. In addition, the model helped form constructive concepts of movement of the folding systems umbrella-shaped, which resulted in a retractable folding system, which is bent on building a node to join two elements creating a structural system. This work was concluded that the transformable systems can help improve the design of flexible structural systems.

KEYWORDS: Structural design, construction details, research and development, retractable folding system, structural simulation.

\section{INTRODUCCIÓN}

En este artículo se presentan los resultados de la investigación Diseño de sistemas retráctiles, adscrita a la línea de investigación Diseño y Tecnología Transformable; este proyecto fue financiado y avalado por la Facultad de Arquitectura de la Universidad Veracruzana y tiene por objetivo el desarrollo de un sistema transformable plegable y la generación de nuevo conocimiento con el apoyo de los alumnos de licenciatura y de la maestría en arquitectura de dicha dependencia.

En la actualidad, las estructuras compuestas por elementos traccionados y comprimidos son altamente eficientes por el gasto mínimo de material que requieren, ya que alcanzan a cubrir grandes claros. A lo largo de la historia, el hombre ha recurrido a la fuerza de la gravedad para conseguir la estabilidad en bóvedas y cúpulas, construidas con piedras y ladrillo - elementos constructivos que trabajan predominantemente a compresión-, en las que es muy desfavorable la relación entre el peso propio y la resistencia, es decir, para asegurar la resistencia de estas estructuras fue necesaria la construcción de muros de grandes espesores, en los que se apreciaba que el peso propio del material era superior al de las cargas externas (nieve o viento) que la estructura podía resistir, originándose grandes masas nada funcionales para los espacios.

Con la aparición de materiales más eficientes, ligeros y de alta resistencia, fue posible reducir los espesores de la estructuras de estas construcciones hasta nuestros días, en las que, por ejemplo, el peso propio de una cúpula es incluso menor al peso del aire que la envuelve, tal es el caso de la cubierta The Eden Project en Inglaterra, diseñada por el arquitecto Nicholas Grimshaw, cuya cúpula, formada por almohadones neumáticos de lámina plástica de poco espesor, con aire comprimido internamente y estructura con base en marcos de aluminio, le proporcionó una notable ligereza y bajo costo.

Este gran avance tecnológico en el mundo de las estructuras fue aprovechado para realizar $y$ manufacturar materiales cuyo peso propio y rigidez son casi despreciables, pero utilizados bajo una lógica estructural que las hace poco deformables, 
aun estando solicitadas por cargas externas. Esta resistencia estructural se logra bajo la geometrización de la estructura, en la que se encuentran formas que favorecen el equilibrio estructural de la forma, logrando una mejor distribución de los esfuerzos. Un ejemplo de este tipo de geometrías es la parábola, la catenaria, la circunferencia, la elipse, cuyas formas ayudan a cubrir grandes claros, generando nuevos tipos de estructura; en el caso de la presente investigación se abordará el tema de los sistemas plegables tensados, con capacidad de replegarse, moverse y erigirse con facilidad y ser trasladados a otro lugar, aumentando considerablemente las posibilidades de adaptarse en casi cualquier entorno.

Por lo anteriormente expuesto, se presenta un breve recorrido histórico acerca de la trascendencia y el desarrollo de la arquitectura ligera y plegable de las estructuras transformables de rápido montaje. Se comienza con las innovaciones en el área de las cubiertas retráctiles y con la aparición del sistema de unión tipo tijera, que permitió el salto a la movilidad estructural. Aunque se organizó de manera cronológica, no es objetivo de este trabajo realizar un estudio histórico, dado que la historia, como ciencia social, tiene sus propias técnicas y herramientas de estudio.

Otro punto es la justificación del planteamiento para vincular la investigación con la docencia y, en este caso, la adecuación geométrica de las estructuras plegables es uno de los parámetros que se fundamenta para para realizar las aproximaciones metodológicas; bajo este planteamiento del problema, se destaca que esta investigación tiene una orientación eminentemente tecnológica en el campo del desarrollo de la construcción experimental de las estructuras de rápido montaje. Para esto, partimos de preguntas muy puntuales, en las que se encontrarán respuestas, si las tienen, a lo largo del trabajo.

Posteriormente, se tratará de desarrollar la geometrización de modelos plegables que puedan simularse con ayuda del software, en el que se realiza un análisis de segundo orden en estructuras plegables, ya que estas pueden encontrarse dentro del campo de los sistemas de estructuras transformables dado que, para materializarse, requieren de mecanismos en sus uniones que les permiten regresar a su estado inicial. Finalmente, teniendo los parámetros necesarios, se hará un planteamiento para proponer y definir aproximaciones o resultados de los estudios previos, bajo el análisis comparativo de prototipos, con el objetivo de demostrar la viabilidad de la propuesta y, a la vez, experimentar con diferentes materiales y modelos a escala, estos últimos servirán como metodología de diseño para el alumnado en sus propuestas de tesis o proyectos de investigaciones arquitectónicas, cuya finalidad es seleccionar el material idóneo que otorgue más beneficios. Para ello se estudió un prototipo a escala real construido bajo un método artesanal, pero analizando con rigor científico la determinación de su resistencia y equilibrio en el espacio, comparando aspectos tales como los constructivos y sus reacciones, cuando la cubierta está completamente desplegada.

\section{ANTECEDENTES}

Se consultó una línea de tiempo relacionada con el proyecto, en ella se evidencian tres etapas históricas que fueron importantes para el desarrollo de la arquitectura transformable.

Flexibilidad. En la primera etapa de la línea de tiempo encontramos que los beduinos fueron una de las culturas que utilizó los materiales textiles para autoconstruir sus espacios habitables provisionales; en el coliseo romano también se tuvo otra aplicación de la estructura provisional flexible (figura 1) que tiene ilustraciones funcionales y prácticas para un espacio arquitectónico

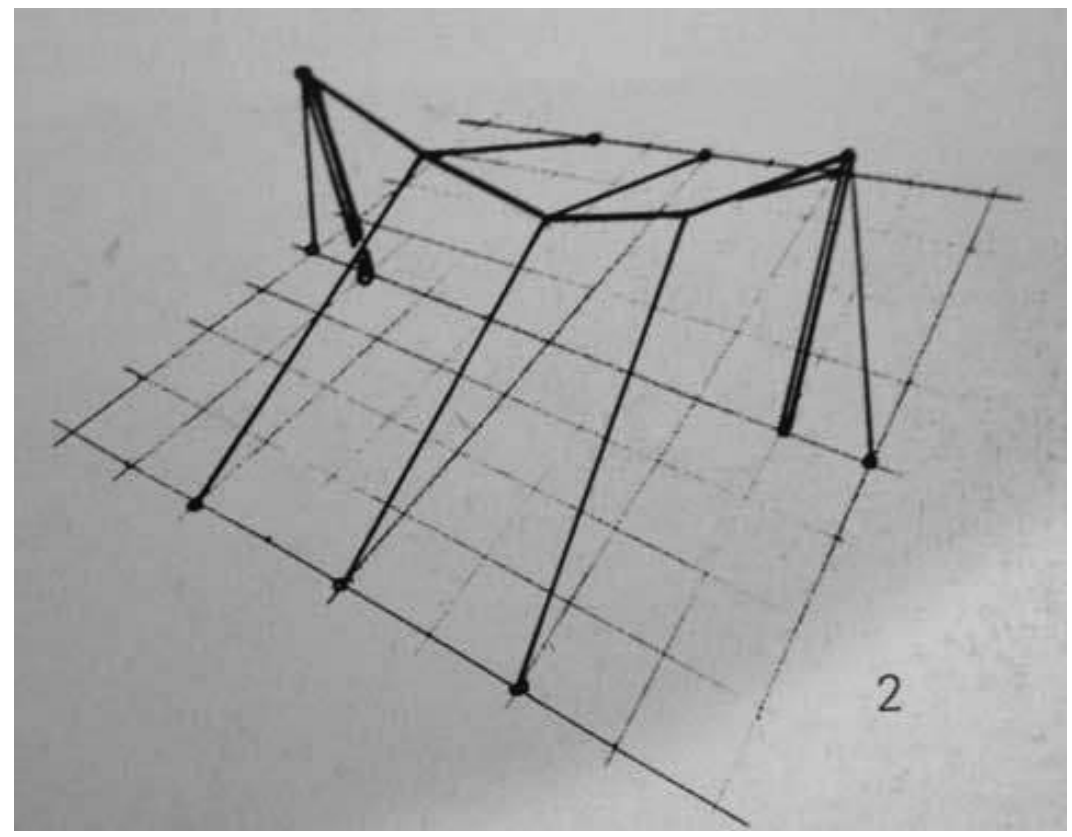

(A) Figura 1. Boceto constructivo de la tribu beduinos, Península Arábica Fuente: Morales (2012a). 


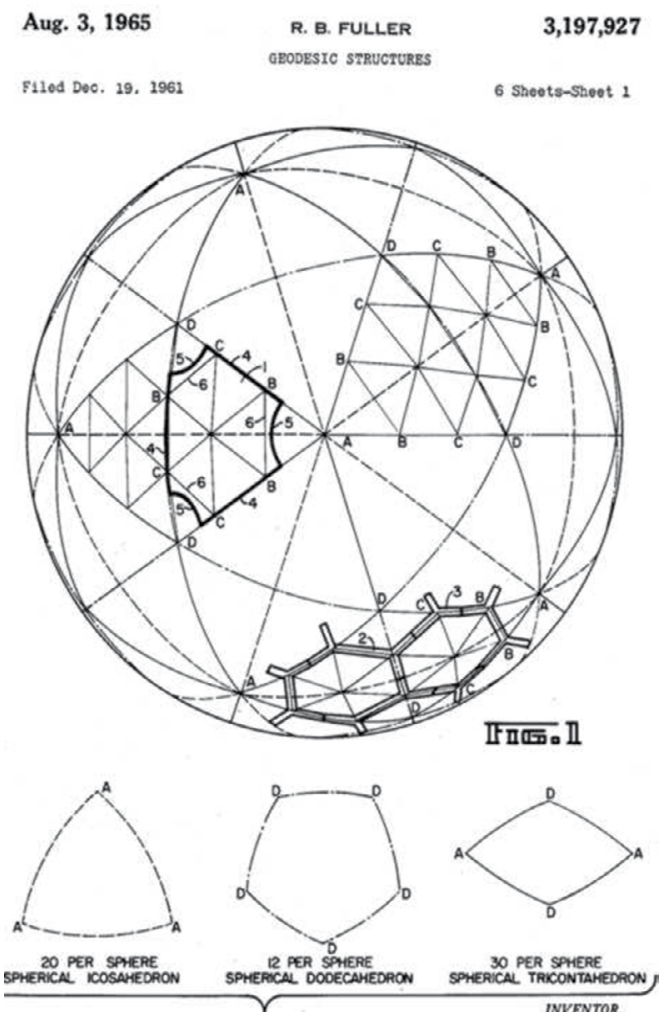

(A) Figura 2. Ingeniero Buckminster Fuller, USA, 1950 Fuente: Buckminster (1963). más adecuado, dejando como principio importante, que la estructura debe ser flexible para adecuar su espacio a otros requerimientos.

Prefabricación. En la segunda etapa encontramos el uso de la geometría aplicada en la tecnología industrial. Con el descubrimiento de materiales más resistentes y ligeros aparecieron infinidad de prototipos prefabricados que ayudaron a construir espacios muy grandes en poco tiempo; posteriormente, la aparición de los arquitectos Emilio Pérez Piñero y Richard Buckminster Fuller con sus aportaciones de sistemas ligeros y eficientes para cubrir espacios arquitectónicos (figura 2); estas aplicaciones nos dan la certeza para demostrar que una estructura prefabricada, diseñada geométricamente, puede desempeñar varias funciones y tiene la capacidad de ajustarse fácilmente a diferentes entornos.

Transformación. En la última etapa encontramos que las estructuras plegables adquieren la capacidad de transformar el espacio, lo cual se produce porque la sociedad demanda espacios más dinámicos y multifuncionales, aunque en la actualidad se generan pocos sistemas retráctiles debido a su difícil manufactura e interpretación de análisis estructural. En este campo de investigación y perfeccionamiento aparece Feliz Escrig como uno de los exponentes más importantes en la actualidad y realiza estructuras transformables de manera dedicada y eficiente (figura 3); cabe mencionar que en el perfeccionamiento de su investigación deja pautas para seguir evolucionando en la generación de las estructuras retráctiles plegables.

Por tanto, esta etudio se beneficia de la línea de tiempo analizada e investigada a profundidad, para proseguir con las siguientes experimentaciones y, a la vez, formalizar una serie de pasos que ayudarán al proyecto final, y para justificar el desarrollo del diseño, en el que se obtendrá la forma y aplicación constructiva de sus detalles estructurales.

\section{JUSTIFICACIÓN}

La búsqueda de nuevas tecnologías se experimenta en las formas básicas plegables que faciliten la adaptación de nuevas transformaciones del espacio arquitectónico. La morfología-conceptual del siguiente modelo es la plegabilidad de una estructura tipo paraguas, con un manto parabólico cónico invertido, con la pequeña peculiaridad del uso de las tijeretas plegables; con este complemento podemos desarrollar su forma de diseño por iteraciones que nos producen múltiples geometrías, pero en este caso solo se utilizan para generar formas retráctiles básicas. A fin de entender un poco el proceso, se experimenta con tres modelos de tijereta, cada una tendrá un modelo geométrico basado en principios matemáticos y graficado con base en un estudio matemático que se usará en cada experimento.

Para entender la realización de la forma de este tipo de estructura se elaboró la figura 4, que contiene los principios básicos que debe tener una estructura plegable; si este concepto no está contemplado, la flexibilidad estructural dentro del sistema no se dará. Teniendo este principio básico se podrá hacer la traslación geométrica matemática o descriptiva de la estructura que se experimenta para generar una serie de iteraciones y modulaciones arquitectónicas, que conducirán a unas propuestas geométricas. 
A fin de generar una innovación más versátil se le agrega el siguiente concepto, que trata de la integración de una cubierta ligera que pueda ser flexible y plegarse conjuntamente con el sistema. Para comprender esta parte del tema se incluyó una membrana textil, la cual desarroIla una geometría hiperbólica. El hiperboloide es la superficie de revolución generada por la rotación de una hipérbola alrededor de uno de sus dos ejes de simetría. Dependiendo del eje elegido, el hipérboloide puede ser de una o dos hojas.

La descripción anterior nos da la pauta para interpretar cuáles son los elementos necesarios para generar bidimensionalmente un hiperboloide (figura 5). Entendidos los fundamentos básicos de este concepto descriptivo podemos aplicar su matemática, lo cual se logra si el centro de simetría es $C(0,0,0)$, y el eje del hiperboloide es el eje $z$, entonces la ecuación del hiperboloide de una hoja es:

$$
\frac{x^{2}}{a^{2}}+\frac{y^{2}}{b^{2}}-\frac{z^{2}}{c^{2}}=1
$$

Y la ecuación del hiperboloide de dos hojas es:

$$
-\frac{x^{2}}{a^{2}}-\frac{y^{2}}{b^{2}}+\frac{z^{2}}{c^{2}}=1
$$

Se retoma en este proceso de desarrollo del diseño, pues esta forma se utiliza en la cubierta del sistema estructural que se va a crear.

\section{MetodologíA}

La hipótesis desarrollada para generar la metodología arquitectónica de la investigación se basó en la experimentación; se aplicó sobre la plegabilidad de los miembros, en un nodo flexible de un paraguas retráctil, dicho mecanismo ayudará a generar esa contracción de los miembros. Podemos notar que el principio geométrico gráfico es suficiente para elaborar el mecanismo que se va a utilizar en esta primera aproximación. Ahora expondremos la solución a partir del análisis comparativo tomando en cuenta la sencillez del mecanismo que tiene que desplegar el modelo. Los paraguas pueden ser de articulación deslizante o de articulación giratoria; esta a su vez puede ser de brazos rígidos o de brazos articulados; por esta razón, el modelo es rediseñado nuevamente y adaptado a nuevas características, para dotarlo del mecanismo deslizante y de brazos rígidos.

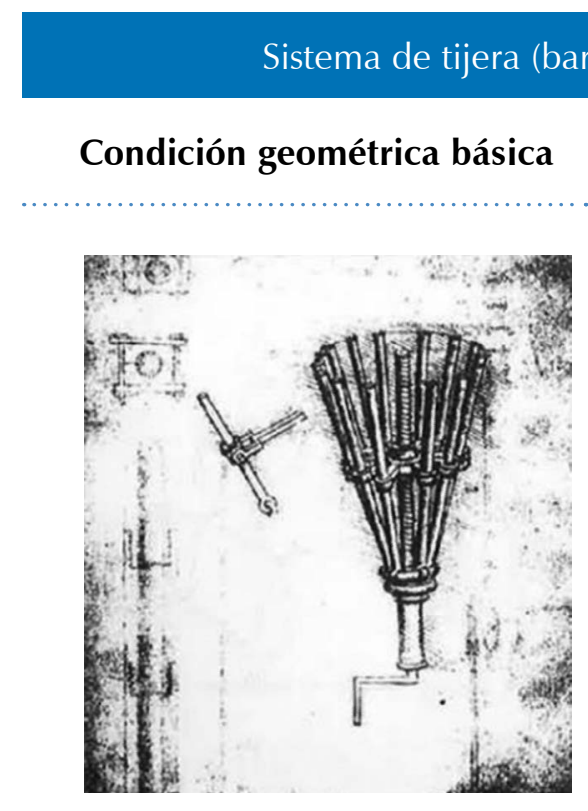

Prototipo de Sombrilla Plegable.

Fuente: Morales (2012b).
Este sistema de tijera es llamada paraguas retráctil, el cual se basa en un nudo central pivotante que sube de manera ascendente y descendente en la barra rígida, estos puntos pivotantes tienen total grado de libertad entre las barras en el eje perpendicular del plano, lo que ayuda a plegarlo hacia su interior.

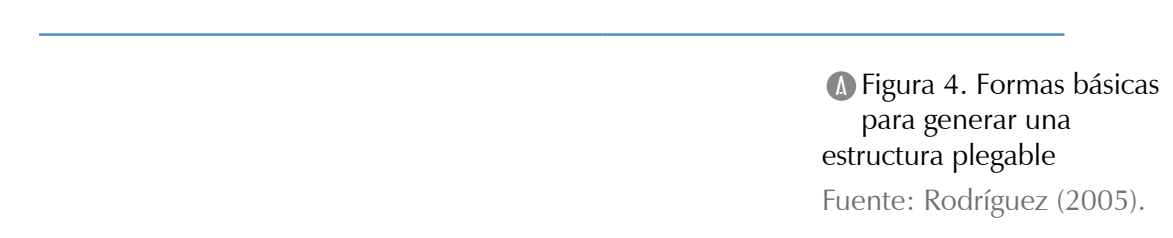

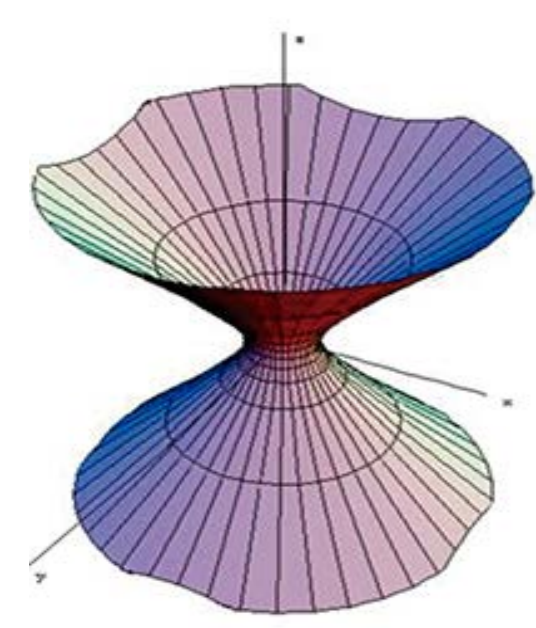

Hiperboloide de una hoja

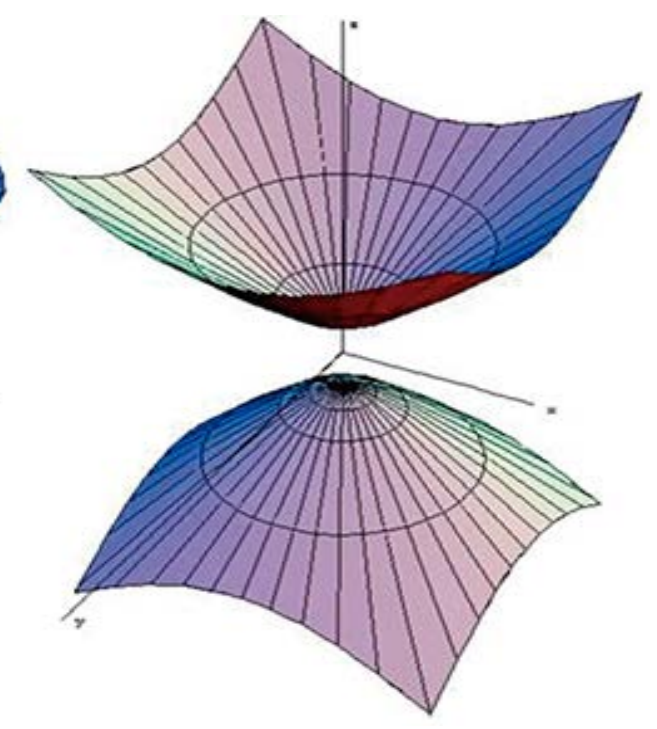

Hiperboloide de dos hojas
Para comprender el proceso de un sistema transformable plegable, se desarrolló un modelo iconográfico que representa el concepto de arquitectura flexible por medio del cual se interpreta el siguiente modelo (figura 6), que se genera con base en una morfología de articulaciones plegables orgánicas; esto une el módulo creado por un brazo flexible a un poste centrado y reforzado, este brazo se repite tres veces alrededor del poste cuadrado, dicha forma adopta las características de un paraguas como analogía convencional y simple.
A Figura 5. La cubierta textil se conforma de una geometría hiperbólica cónica que ayudará a generar una rigidez en la estructura transformable Fuente: Morales (2013b). 

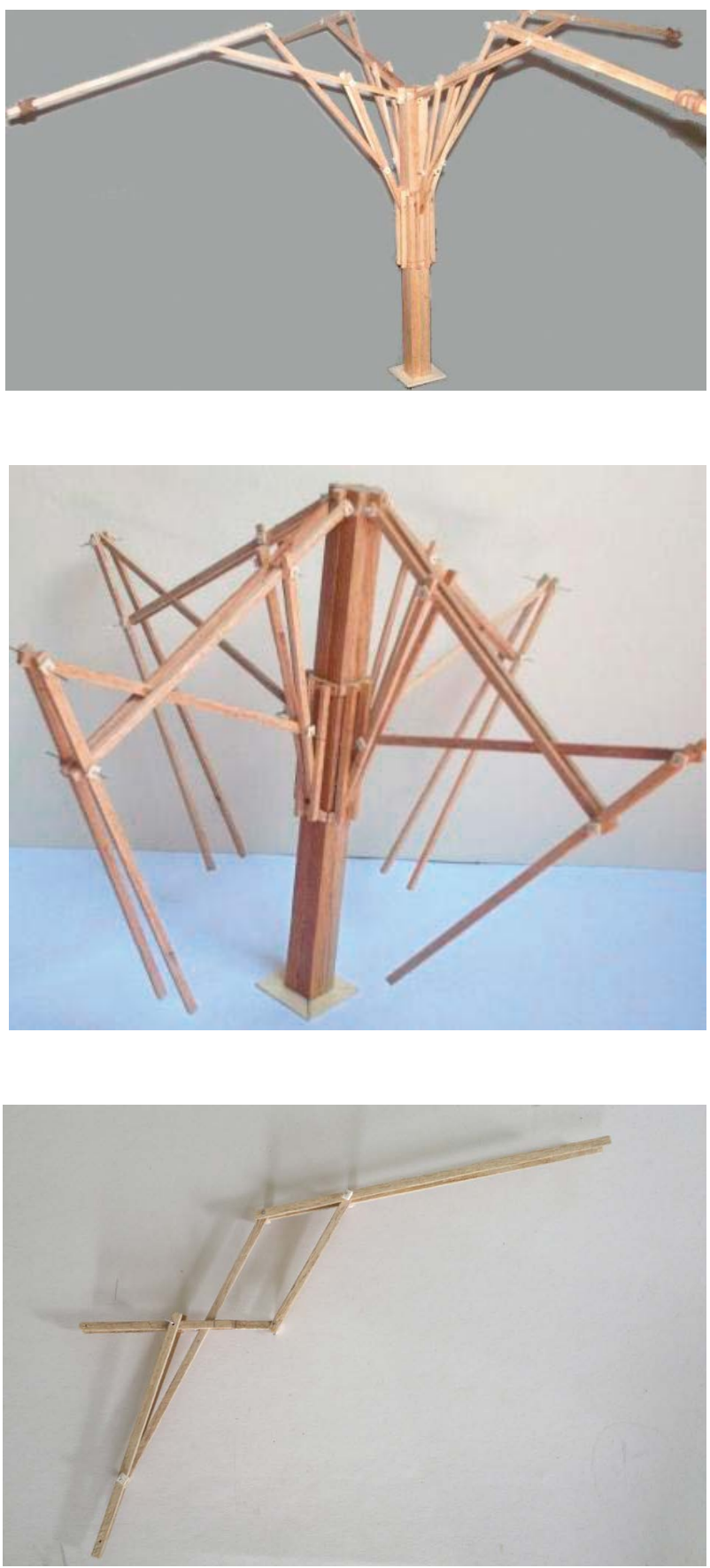
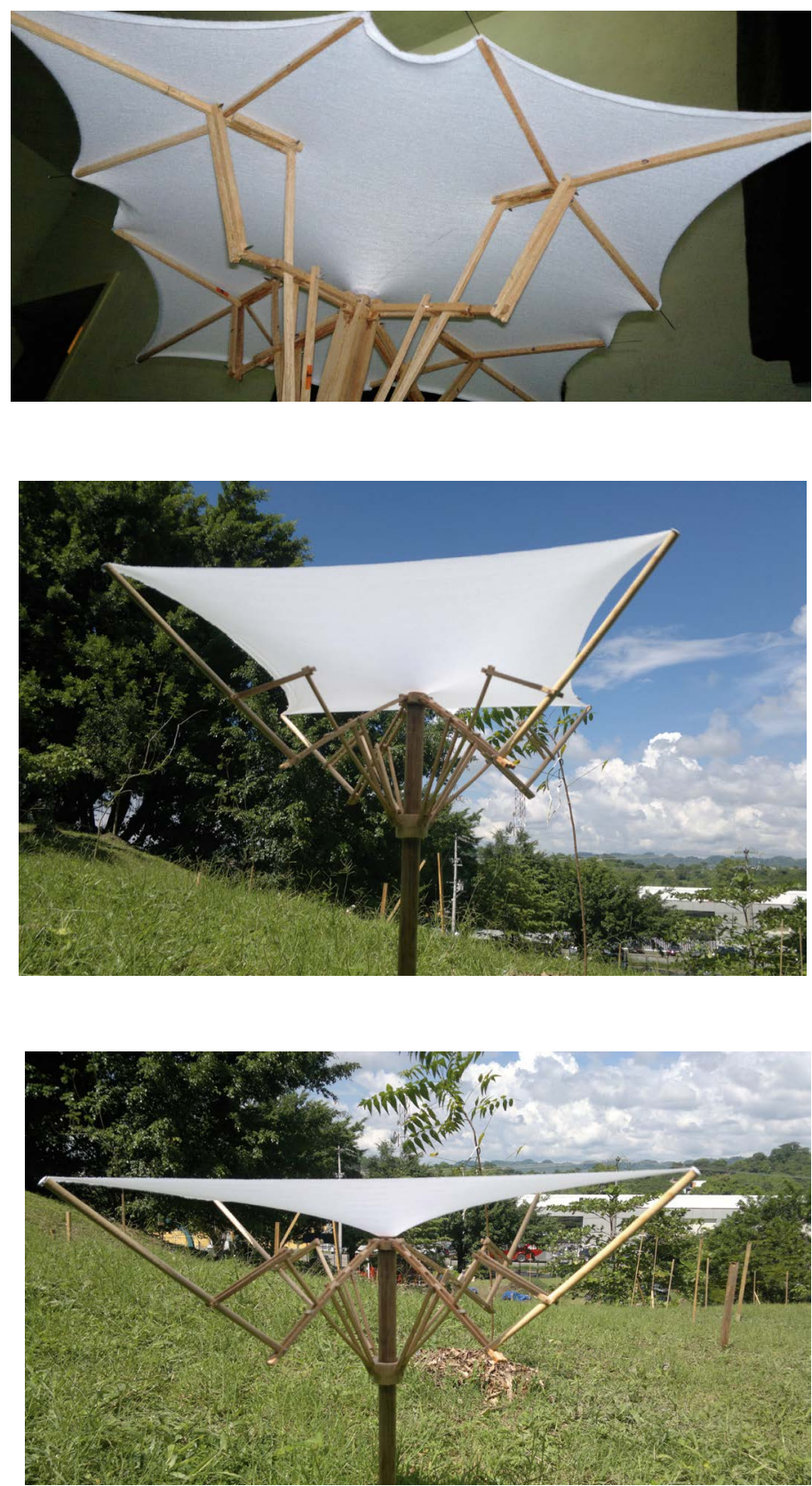

(A) Figura 7. La cubierta textil ayuda a rigidizar el sistema plegable del paraguas, generando la forma final del modelo

Fuente: Morales (2012b).
(A) Figura 6. Desarrollo experimental de brazos mecanizados plegables con nodo ascendente

Fuente: Morales (2012b).
El modelo flexible y cambiante se desarrolla ahora por medio de una sobretenso-estructura que envuelve a la estructura, esto es, mediante una membrana elástica atirantada desde los puntos más altos de la estructura y en un punto central que puede generar una posibilidad de forma orgánica muy atractiva (figura 7). La instalación de la membrana trajo consigo problemáticas de estabilidad y resistencia, tanto para la estructura como para la membrana misma, pues la elasticidad de la membrana trabajó sobre la estructura deformándola al punto de romper los nodos pivotantes, por ello, el modelado es fundamental para el desarrollo final de la investigación, ya que con este se obtienen resultados interesantes para experimentar y generar futuras sublíneas de sistemas transformables.

Por ende, el principio comentado anteriormente da la pauta para crear elementos más simples y con más funcionalidad. Haciendo énfasis en un método para obtener la forma final del proyecto y su resolución constructiva, se trata de buscar soluciones óptimas que brinden la simpleza del modelo, con la finalidad de determinar las características que se establecen en el proceso de este trabajo (Figura 8); una vez entendido este principio, se genera el modelo con base en el perfeccionamiento de los miembros retráctiles con brazos mecánicos, y con ello se forma el paraguas retráctil invertido que da una solución más eficiente para la transformación del espacio.

Ya en el desarrollo del modelo se experimentó con solo cuatro extremidades, pero se generaba inestabilidad estructural en el poste por tener una esbeltez excesiva; para solucionar esto se le agregaron otros cuatro miembros mecánicos plegables para estabilizar el manto textil de su cubierta y disminuir la tensión que la membrana ejerce sobre 

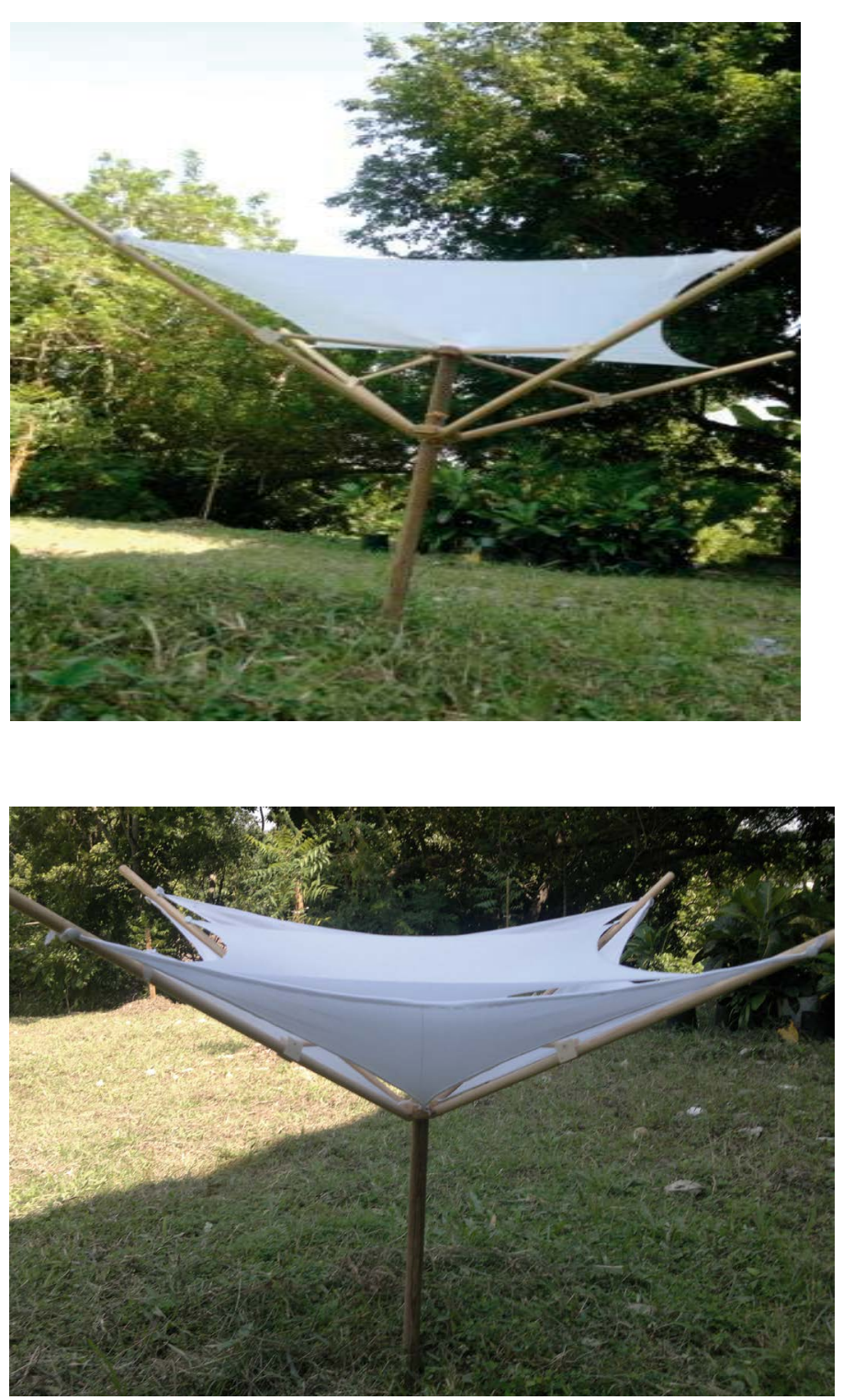

(4) Figura 8. Modelo experimental de un paraguas retráctil de cuatro miembros

Fuente: Morales (2012b)
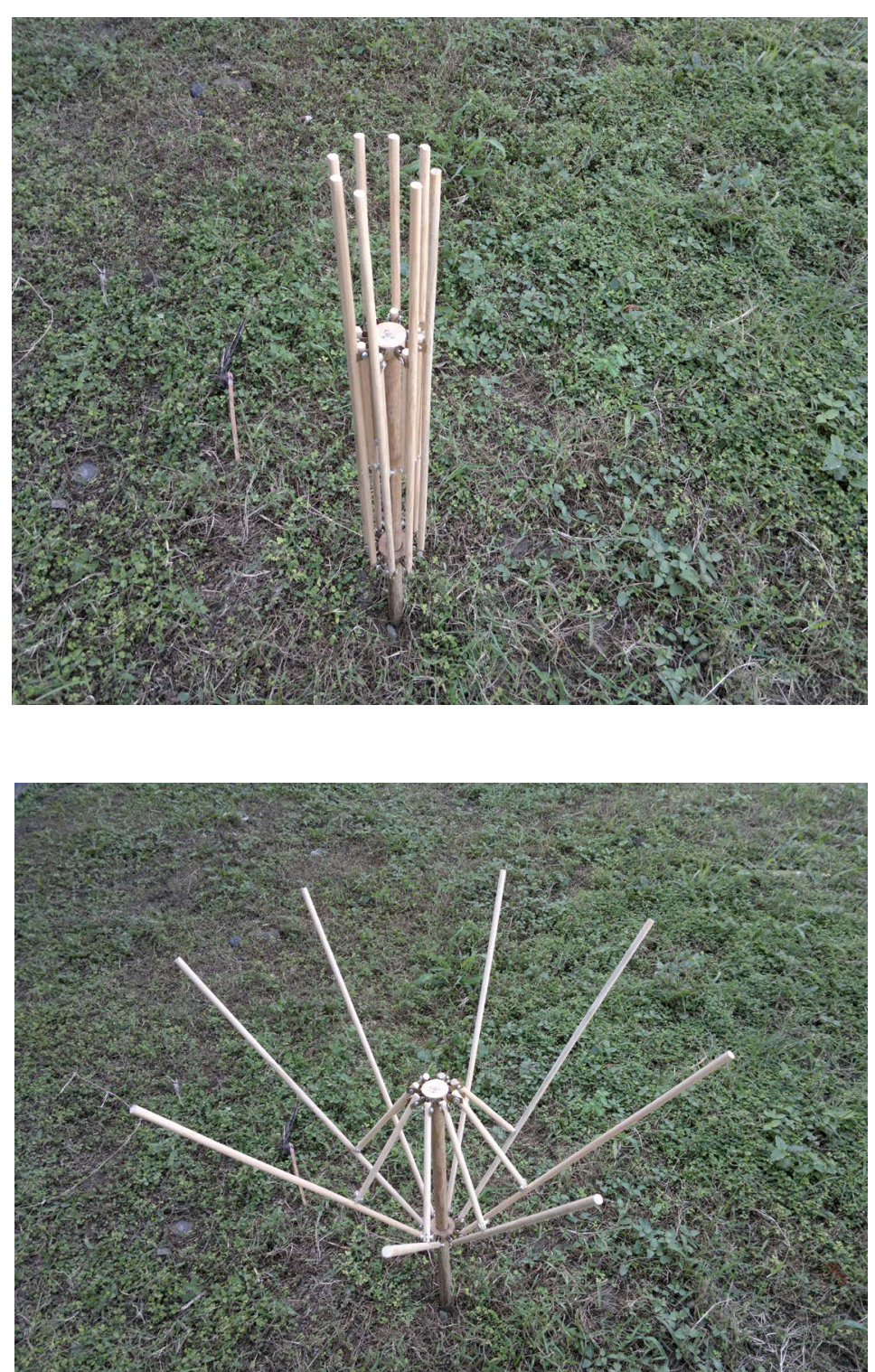

(A) Figura 9. Mejoramiento del modelo experimental; al agregarle ocho miembros mantiene un mejor equilibrio estructura

Fuente: Morales (2012b). la parte elevada de los brazos (figura 9); por ello se optó por realizar un paraguas retráctil de ocho miembros, dando como resultado una estructura más resistente y estable. Ahora se procede a comprobar en este nuevo modelo el mecanismo de deslizamiento o retráctil; dicho mecanismo favorece que el modelo tenga una propiedad única pues su morfología adopta una posición rígida en cuanto el mecanismo se acciona.

Con el propósito de que el modelo funcione a partir de mecanismos sencillos, se implementa un aditamento más para que le sirva a la plegabilidad de sus miembros, por ello utilizamos una herramienta simple y eficiente (figura 10) como es el uso de un sistema de poleas; la polea tiene la propiedad de resistir grandes cargas con tan solo la mitad o un tercio de la fuerza, que el sistema reparte equitativamente en sus poleas, o sea, si se tienen unas 10 toneladas y se coloca
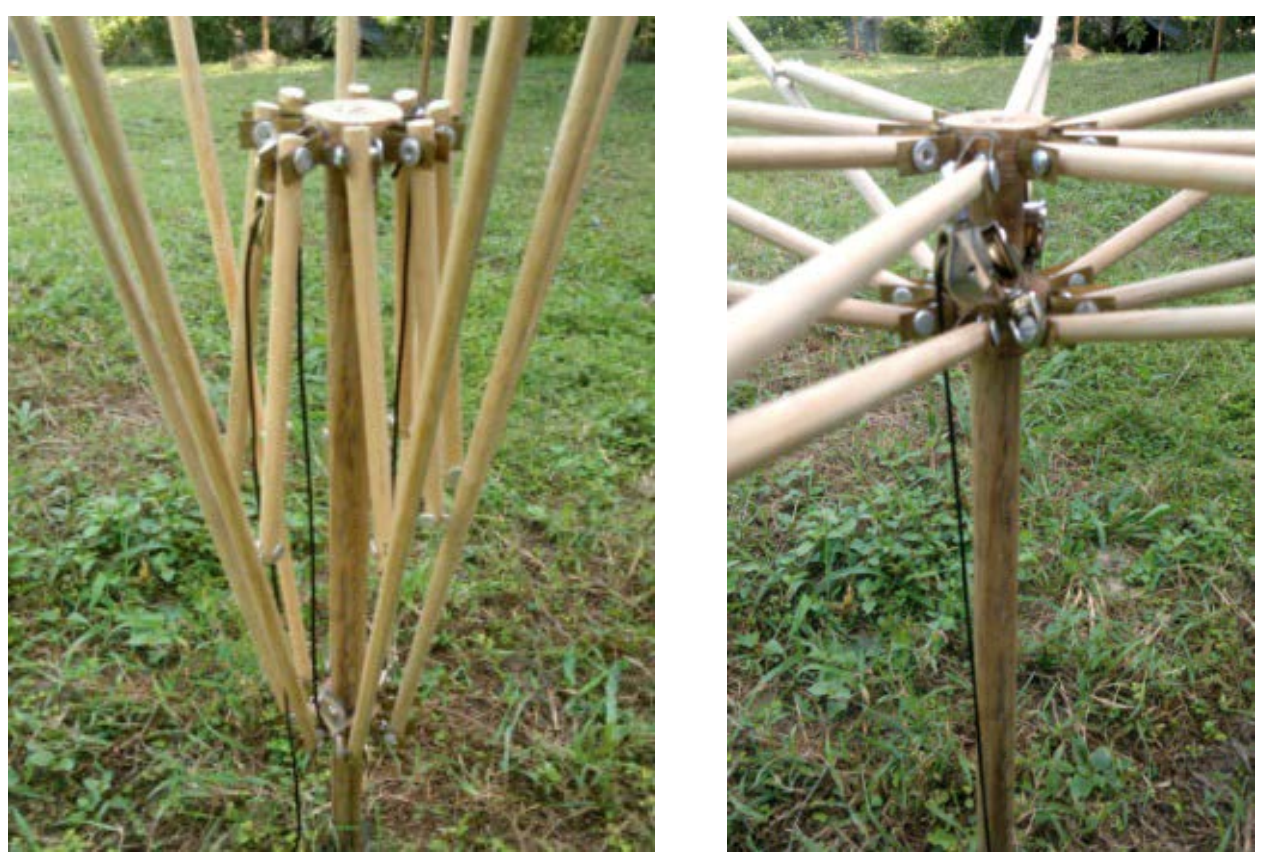

(A) Figura 10. Se agregó un sistema de polea para tener la propiedad de plegado Fuente: Morales (2012b). 
una polea, la polea absorbe 5 toneladas de carga distribuida, esta opción da solución a la problemática de izaje del modelo, por esta razón se integró este sistema de poleas para propiciar la retracción del paraguas con esfuerzos mínimos.

El resultado a partir de adaptar este mecanismo fue exitoso, pues las extremidades del modelo reaccionaron proporcionalmente al esfuerzo ejercido con la ayuda de poleas (figura 11); una vez comprobado este funcionamiento, se dispone a colocar la membrana textil con la finalidad de que el modelo pueda funcionar correctamente y sin inconvenientes, para que así el modelo quede configurado de manera más apta para un funcionamiento eficiente.

\section{RESULTADOS}

\section{SIMULACIÓN ESTRUCTURAL}

En el proceso de esta investigación se ha analizado el efecto de la geometría y las partes constructivas del sistema retráctil del paraguas, gracias a la realización del prototipo por medio de la experimentación. Una destacada característica que ayudará a darle la estabilidad a este paraguas es el uso de una membrana textil, ya que al proyectar sistemas transformables debemos tomar en cuenta su ligereza, es por ello que antes de modelar los detalles tecnológicos y constructivos de la cubierta retráctil, haremos una pauta para diseñar nuestra cubierta textil. Esta etapa es esencial para el diseño del siste- ma, ya que anteriormente, cuando se realizó el diseño experimental, se colocaron las dimensiones de dicho paraguas retráctil, que tendrá una altura efectiva de $3,5 \mathrm{~m}$ y un diámetro de $8,5 \mathrm{~m}$. Para este caso, calcularemos la estructura por el método virtual de densidades de fuerza, en donde obtendremos la forma, para ello nos apoyamos en un software institucional realizado por Ramón Sastre Sastre, profesor de la Escuela Técnica Superior de Arquitectura en la Universidad Politécnica de Catalunya. Este software, Ilamado WinTess versión $3,11^{1}$, realiza el método virtual por densidades de fuerza; aplicado este método, genera una relajación en la membrana para obtener la forma deseada de la cubierta textil (figura 12 y figura 13); primeramente generamos una malla octagonal de 8,5 m su dirección lineal; una vez generada la malla, se realiza el cálculo para la obtención de la forma por densidad de fuerza y relajación, lo que da como resultado la forma que tendrá esta cuando esté pretensada.

Posteriormente, se introducen las cargas anteriores asignadas al programa, las cuales son establecidas por reglamento de NCRDF, así: carga muerta: $30 \mathrm{~kg} / \mathrm{m}^{2}$, carga viva máxima: $40 \mathrm{~kg} / \mathrm{m}^{2}$, carga viva accidental: $20 \mathrm{~kg} / \mathrm{m}^{2}$ (tabla 1 ). Una vez realizado este, las cargas horizontales de sismo se

1 WinTess3 es la última versión del software creado como eje de la tesis doctoral de Ramón Sastre Sastre, el cual implementa el método matricial y de relajación para obtener la forma de cubiertas textiles, calcularlas y generar su modelaje. Fuente: http://tecno.upc.edu/wintess/manual/

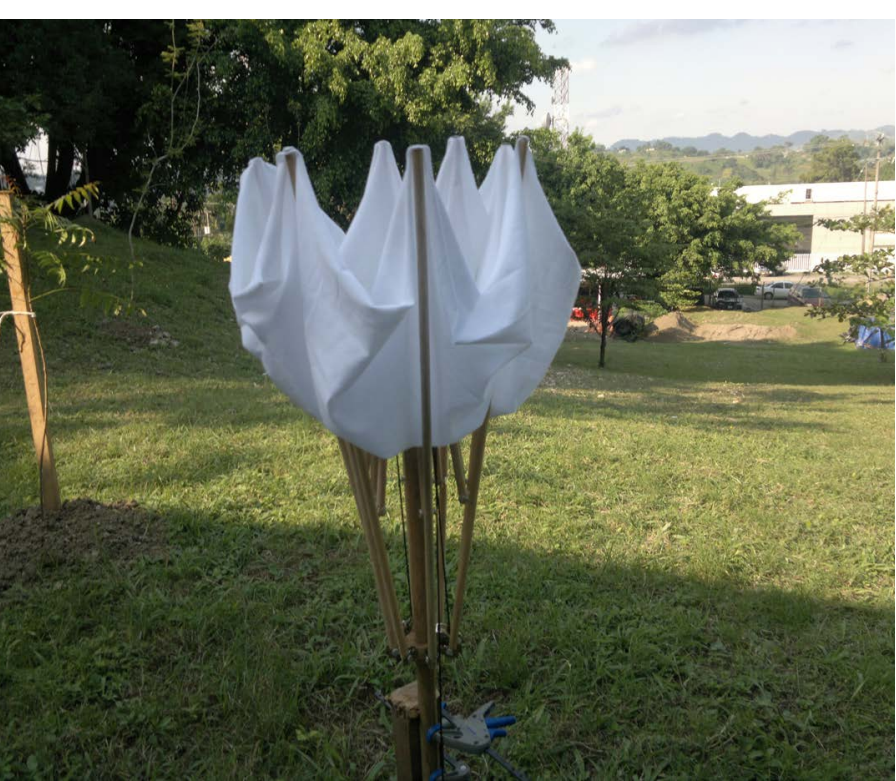

(A) Figura 11. La forma final de modelo experimental ayuda a generar las premisas y cotas del proyecto

Fuente: Morales (2012b).

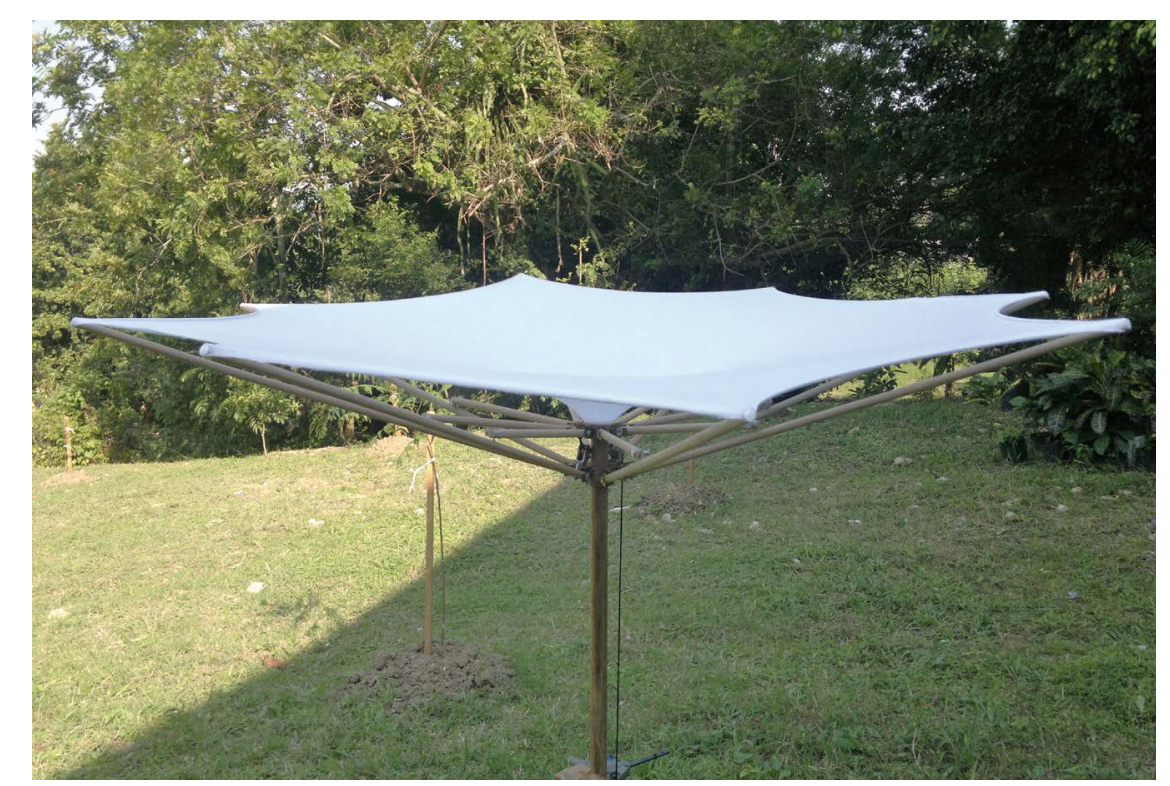


considerarán como cargas externas nodales, y la presión de viento cambiaría un poco; ya que cada país tiene su propio código de aplicación de carga, para ellos solo utilizaremos la velocidad real básica del viento que en nuestro caso se dio así:

\section{WinTess}

\section{Combinación de Carga :1,4 + 1.5 + SISY + 1,1 VIEN X + 1,1 VIEN Y}

\begin{tabular}{|c|c|c|}
\hline \multicolumn{3}{|c|}{ Sobrecarga $=20 \mathrm{~kg} / \mathrm{m}^{2}+$ Carga accidental: $40 \mathrm{~kg} / \mathrm{m}^{2}$} \\
\hline Viento $X=64,7 \mathrm{~km} / \mathrm{h}$ & Viento $Y=16,4$ km/h & Viento total $=66,74 \mathrm{~km} / \mathrm{h}$ \\
\hline \multicolumn{3}{|c|}{ Tipo de edificio $=$ Abierto $(3)>\operatorname{Sin} \mathrm{c}=0$} \\
\hline \multicolumn{3}{|c|}{ Pretensado de la membrana $=0,08 / 0,08 \%$} \\
\hline \multicolumn{3}{|c|}{ Peso de los cables $=29,9 \mathrm{~kg}$} \\
\hline \multicolumn{3}{|c|}{ Peso de los tubos $=464,7$ kg } \\
\hline \multicolumn{3}{|c|}{ Peso de la membrana $=34,3 \mathrm{~kg}$} \\
\hline
\end{tabular}

A Tabla 1. Introducción de datos de carga para análisis estructural Fuente: Morales (2013a)

Posteriormente, se hace el proceso de iteración del cálculo, el cual realiza una matriz de nodos por fuerzas desequilibrantes; el programa efectúa un número de iteraciones hasta lograr que la estructura esté equilibrada; el número de iteraciones puede variar dependiendo de la forma compleja que pudiera llegar a tener la estructura, pero lo más importante de este cálculo es que obtenemos la dimensión real de los miembros de la estructura, los esfuerzos que actuarán en ella, las dimensiones de los cables y las deformaciones que puede tener, ya incluida la membrana; para este caso se seleccionó una membrana Serge Ferrari-Fluitop-T2-702, con una resistencia de $\mathrm{RK}(\mathrm{daN} / 5 \mathrm{~cm}) 300 / 280$, y unos tubos circulares de $110 \mathrm{~mm}$ de acero A36 para el poste central y $90 \mathrm{~mm}$ para los miembros retráctiles, y cables de acero galvanizado de $18 \mathrm{~mm}$ de espesor. Ya realizado el cálculo sobre estas especificaciones, se verifican los datos arrojados del programa, aunque vale la pena comentar que la verificación de los miembros fue realizada por el EHE08², que no nos causa ningún problema ya que los valores que maneja en factores de seguridad son casi iguales a los del manual de acero de LRFD $^{3}$.

2 Método de diseño de acero por plastificación y resistencia del euro código es usado para analizar y calcular las dimensiones de los miembros estructurales metálicos. Fuente: http://tecno.upc.edu/wintess/manual/

3 El reglamento del LRFD se utiliza para diseñar la plastificación y el diseño por resistencia del acero, sus coeficientes de seguridad son iguales a los del EHE08, así que pueden ser aplicados en casi todos los países si no existiera reglamentación suficiente. Fuente: http://tecno.upc.edu/wintess/ manual/
La utilización de código no ocasiona ningún problema de diseño estructural, ya que las dos normas se regulan por coeficientes de seguridad casi iguales, aunque el Euro código maneja factores de seguridad muy altos, mismos que están sobrados en cuanto a solicitaciones y comprobaciones en México, aunque estas sí impactarían seriamente en la cuestión económica; sin embargo, para este ejercicio dejaremos la normativa que el programa maneja. Posteriormente, en el análisis observamos que las barras con mayor esfuerzo de momento y tensión no superan el ratio de seguridad establecido a la unidad (1) (figura 14); para este tipo de estructura la comprobación sigue siendo la unidad, pero la

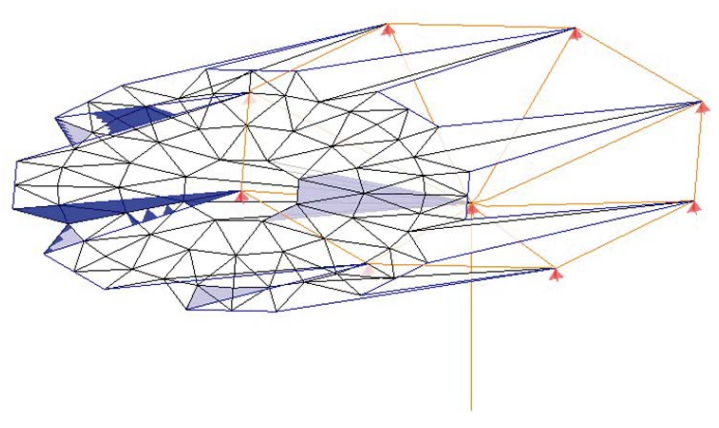

(V) Figura 12. Se generó la malla octagonal y se dio paso para obtener la forma virtual de la cubierta parabólica Fuente: Morales (2013a).

(7) Figura 13. Después de generarse la estructura completa junto con la membrana se obtiene mayor estabilidad Fuente: Morales (2013a).

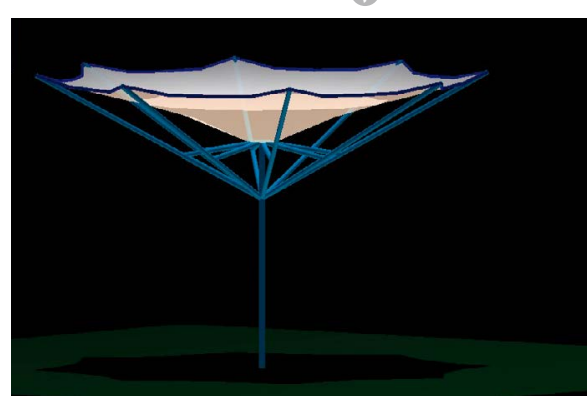




\begin{tabular}{|c|c|c|c|c|}
\hline \multicolumn{5}{|c|}{ Barras } \\
\hline & & Axial (T) & $\begin{array}{l}\text { Tensión } \\
\left(\mathrm{kg} / \mathrm{cm}^{2}\right)\end{array}$ & Ratio \\
\hline 2 & $\varnothing 110 \cdot 5 \_S 235$ & $-0,107$ & 1789,2 & 1,27 \\
\hline 6 & Ø90.4 S235 & $-0,209$ & 1425 & 1,04 \\
\hline 8 & $\varnothing 90 \cdot 4$ S235 & $-0,207$ & 1413,6 & 1,03 \\
\hline 10 & $\varnothing 90 \cdot 4$ S235 & $-0,151$ & 790,3 & 0,59 \\
\hline 11 & Ø90.4 S235 & $-0,465$ & 828,7 & 0,65 \\
\hline 12 & Ø90.4 S235 & $-0,215$ & 1374,7 & 1,01 \\
\hline 15 & $\varnothing 90 \cdot 4$ S235 & $-0,449$ & 750,6 & 0,59 \\
\hline 16 & $\varnothing 90 \cdot 4$ S235 & $-0,216$ & 1437,7 & 1,05 \\
\hline 22 & $\varnothing 90 \cdot 4$ S235 & 0,074 & 964,5 & 0,68 \\
\hline 23 & Ø90.4_S235 & 0,194 & 716,7 & 0,5 \\
\hline 25 & Ø90·4_S235 & 0,101 & 889,5 & 0,62 \\
\hline
\end{tabular}

(4) Tabla 2. Resultado de resistencia de los miembros rígidos del sistema plegable Fuente: Morales (2013a).

\begin{tabular}{|c|c|c|c|}
\hline \multicolumn{4}{|c|}{ Tracción máxima en la membrana } \\
\hline Barra & Nudos & T/metro & $\mathrm{kg} / \mathbf{5 c m}$ \\
\hline 56 & $120-135$ & 1,07 & 73,5 \\
\hline \multicolumn{4}{|c|}{ Tracción en los cables de relinga } \\
\hline Cable & $\mathbf{T}$ & Ratio & Barra \\
\hline 1 & 1.860 & 0,11 & $2,3(18 \mathrm{~mm})$ Galv \\
\hline 2 & 1.857 & 0,12 & 1,4 $(18 \mathrm{~mm})$ Galv \\
\hline 3 & 1.593 & 0,25 & $5,6,7,8(18 \mathrm{~mm})$ Galv \\
\hline
\end{tabular}

(A) Tabla 3. Resultado de la resistencia y tensión de la velaría y los cables Fuente: Morales (2013a).

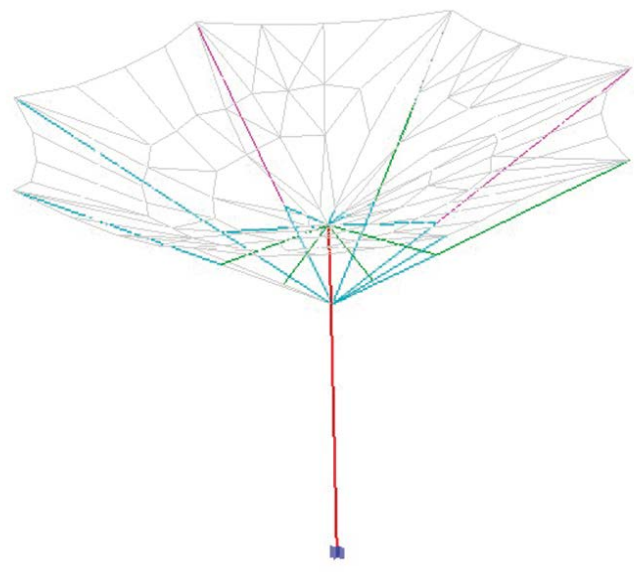

A Figura 15. El diseño del paraguas está sustentado por el euro código EHE08, pero se rediseñó con el código de LRFD para tener un diámetro acorde a la zona Fuente: Morales (2013a).

vamos que las relingas y las superficies tensadas del paraguas retráctil siguen siendo bajas en tensión; la carga de tracción en las relingas es poca, gracias a que los puntos de conexión tienen los miembros con perfil suficientemente resistentes para no deformarse por la presión generada por el viento (tabla 3), ya que estas cargas hacen que la estructura requiera de una mayor inercia en el poste, por lo cual se configura una retracción con mayor área de plegabilidad

\section{DESARROLLO DEL PROYECTO}

Posteriormente, se generó la modelación del prototipo a una escala 1:5 para ver los detalles de conexión constructiva del paraguas retráctil, ya que las articulaciones y conexiones del sistema son las que le dan la plegabilidad, por ello era conveniente formar el modelo con materiales que tuvieran la resistencia adecuada a la tracción, pues la tenso-estructura (velaría) hace que los miembros que forman parte de la estructura se rigidicen (figura 16), por ello se colocó un nodo móvil ascendente que alberga los ocho miembros articulados; estos a su vez se articulan nuevamente a un tercio de su claro, para conectar otros miembros tubulares con el nodo superior fijo, que ayuda a sostener la plegabilidad del sistema retráctil. Posteriormente, se coloca un accesorio de refuerzo para conectar las articulaciones de la linternilla del velaría, que a su vez se fija con cables para tener un tope, que es la articulación colocada en la unión metálica del paraguas, y, consecuentemente, se coloca un sistema de poleas que actúan como palanca para subir el nodo ascendente y plegar la estructura de la vela a fin de mantener rígido el sistema estructural. 

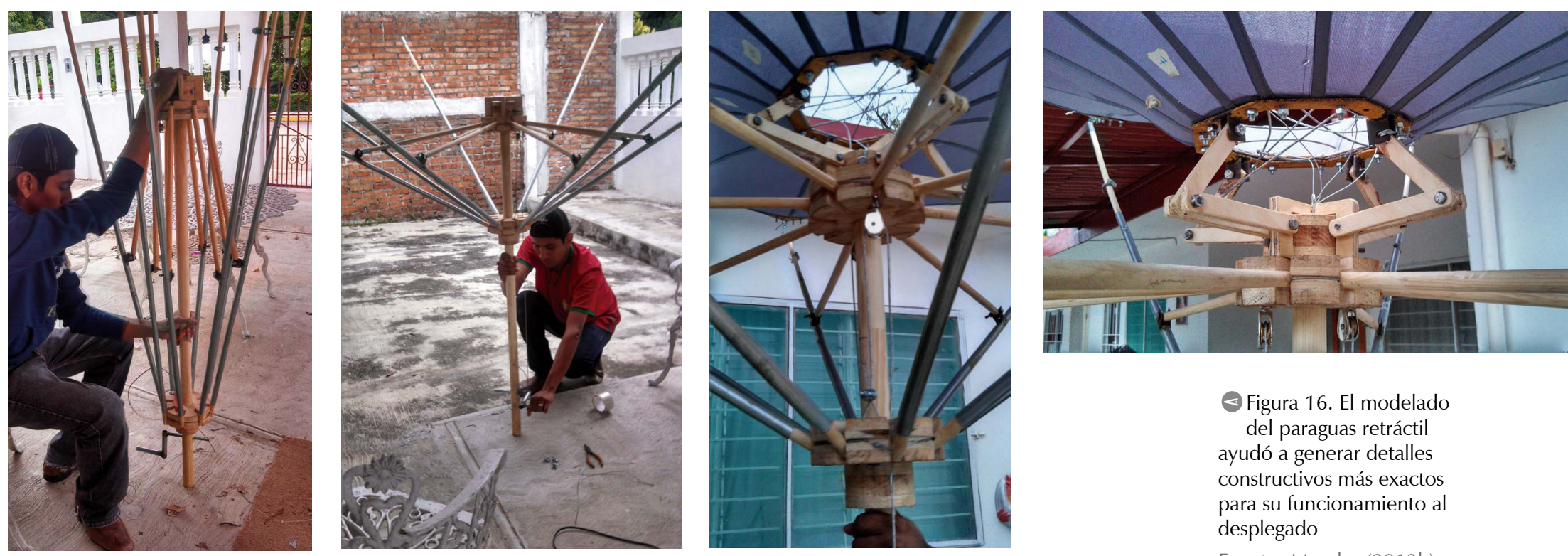

( Figura 16. El modelado del paraguas retráctil ayudó a generar detalles constructivos más exactos para su funcionamiento al desplegado

Fuente: Morales (2013b)
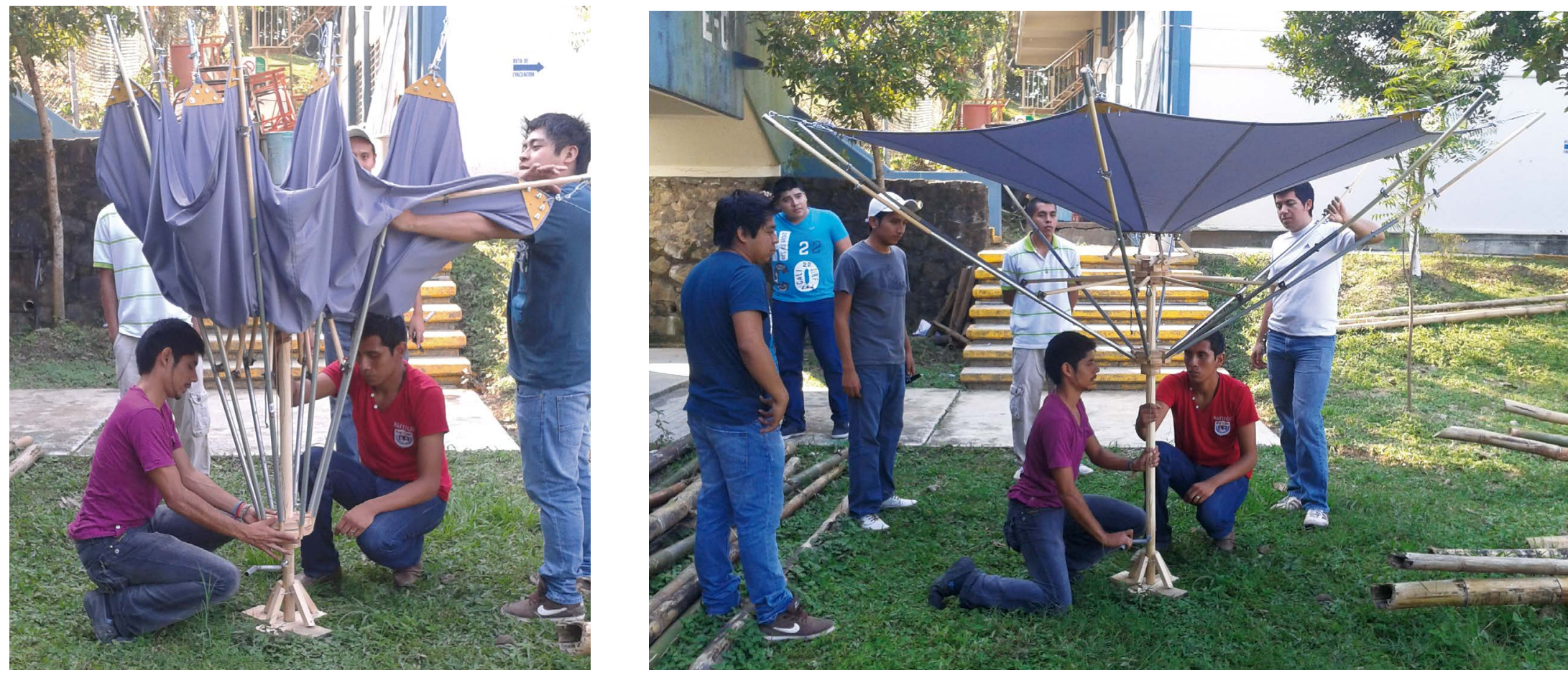

Ya colocada la velaría en la parte superior de la estructura, se instalan tensores reguladores en las uniones metálicas de los bordes tubulares para tensar las relingas en los apoyos extremos de los miembros y así equilibrar el sistema estructural transformable; posteriormente, se prueba la estructura de la velaría con el sistema de poleas (figura 17), observamos cómo el comportamiento de la tenso-estructura es estable y mantiene una figura estructural adecuada para mantener en equilibrio las tensiones dentro de su superficie. Una parte importante de esa rigidización de la velaría es el regulador de los bordes, por ellos se puede plegar el manto del paraguas retráctil.

Posteriormente, al construir el modelo a escala $1: 5$, se generó la modelación de las uniones en detalle, a escala 1:1 en AutoCAD, para conse- cutivamente construirlo en metal, con un perfil de acero A36; el tubo principal tiene $110 \mathrm{~cm}$ de perfil (fgura 18 y figura 19), los miembros secundarios son de $90 \mathrm{~cm}$ de perfil, las uniones están hechas de placas metálicas de 1/4", con una soldadura de arco eléctrico con isótopo EXX60 estructural.

En la unión articulada ascendente se coloca una polea de carga de 2,5 toneladas, con un cable de $14 \mathrm{~mm}$ de espesor, para cargar los miembros secundarios del paraguas retráctil; esta se regula con una palanca reguladora en la parte inferior, manejada con una manivela que, al girarla, pliega y despliega la estructura. Por último, se propuso colocar en el extremo de los postes metálicos secundarios una estructura interna telescópica, esto ayudará para ver si la vela necesita más tensión.
(4) Figura 17. El desplegado del modelo ayudó a formar conceptos constructivos del movimiento del sistema plegable del paraguas Fuente: Morales (2013b). 

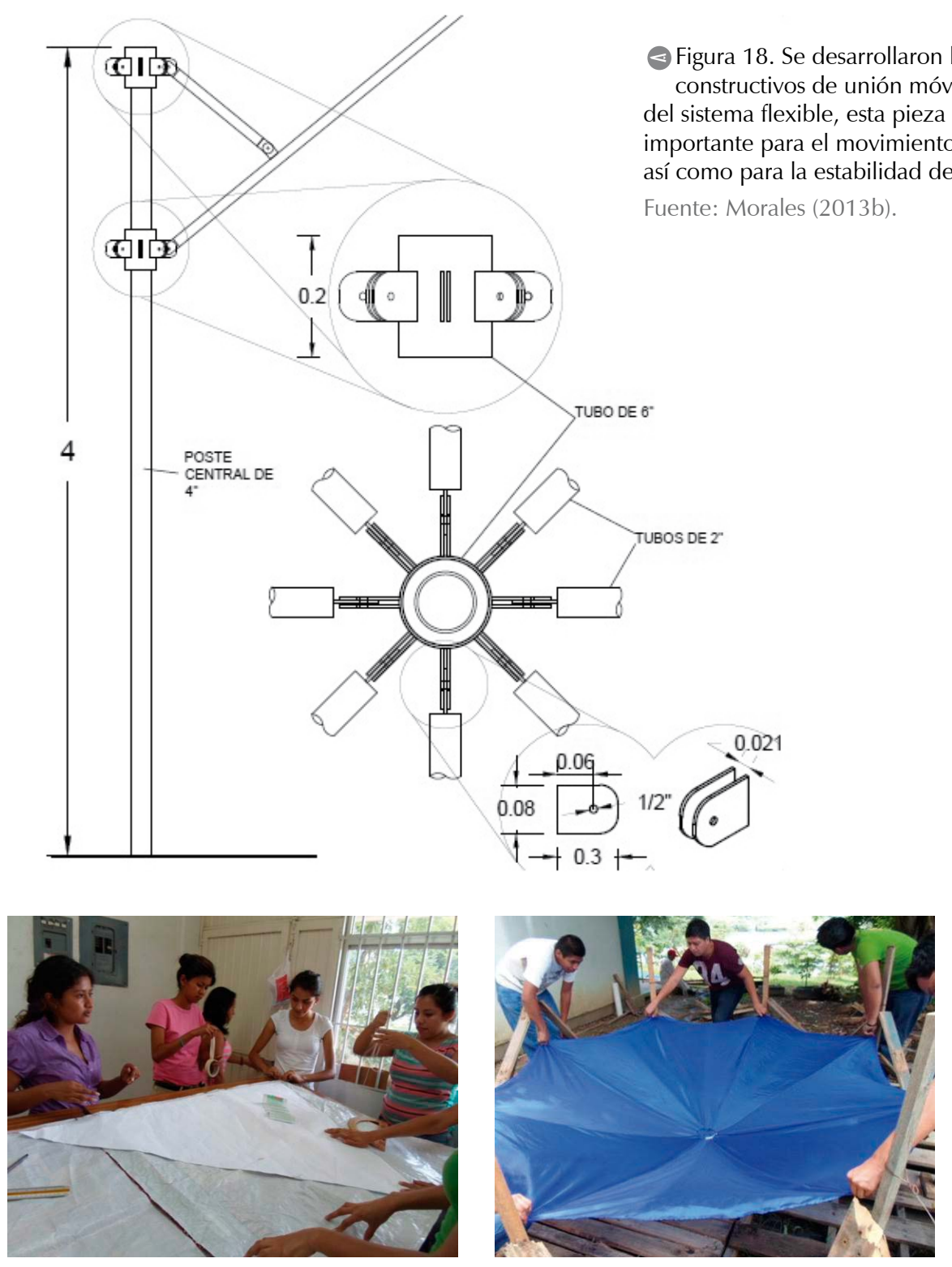

(A) Figura 20. El patronaje de la velaría es sumamente importante, ya que el manto servirá como rigidizador del sistema y, por ello, debe tener una superficie exacta, para que posteriormente pueda ser tensada en el paraguas Fuente: Morales (2013b).
Posteriormente, se realiza el patronaje constructivo de la velaría analizada por Win Tess (figura 20), dicho programa genera el patrón necesario para elaborar el manto de la velaría y de ahí realizar la uniones necesarias para su construcción. En seguida se genera un modelado previo para analizar sus curvaturas, para concebir la forma final o aproximada de la superficie construida en el sistema plegable del paraguas. Por último, cabe señalar que se usaron dos métodos de patronajes, el primero fue un método desarrollado por traslación geométrica y el segundo con un programa de software, este último definió la forma final de la vela en el sistema estructural.

\section{CONSTRUCCIÓN DEL PARAGUAS RETRÁCTIL}

El siguiente paso fue la fabricación del paraguas retráctil. El análisis estructural nos dio un miembro de poste central de A36 de OCE 89 mm, con una tensión aceptable para manufacturarlo y mantener la resistencia y la estabilidad estructural. Las uniones de cumbrera y el nodo deslizante se fabricaron por medio de armado de piezas, y en los brazos secundarios plegables se colocaron los miembros OCE $60 \mathrm{~mm}$, al igual que los de la cumbrera, que ayudan a la plegabilidad del paraguas. El diseño de las placas de cumbrera y nodo deslizante fue de $1 / 2^{\prime \prime}$, estas se soldaron con electrodos E60XX para darle la homogeneidad correspondiente a las uniones; de igual manera, este mismo tratamiento se le dio a la fabricación de la base del poste central, en donde se absorbe el momento más grande del sistema. Primeramente, se construyó un pedestal de producción industrial para armar el nodo deslizante, en este se colocaron las medidas exactas del nodo articulado; para lograrlo se aplicaron varias soldaduras de placa en donde se pusieron los componentes que se articulan y que, posteriormente, le darán la facilidad de plegarse; después se fabricó la cumbrera (figura 21), compuesta de varias piezas, que tendrá conexiones múltiples que ayudarán a rigidizar el sistema. Posteriormente se efectúa un primer montaje para verificar el plegado de la estructura; en paralelo, se cimbró y coló la cimentación del paraguas retráctil, construyendo un dado de cimentación de 1,2 m de altura por 0,40 $\mathrm{m}$ de ancho (figura 22), con una placa de cimentación de 0,80 × 0,80 m para evitar el efecto del volteo por cargas horizontales. Se le puso una placa de acero de $1 / 2$ " de espesor, sujeta 

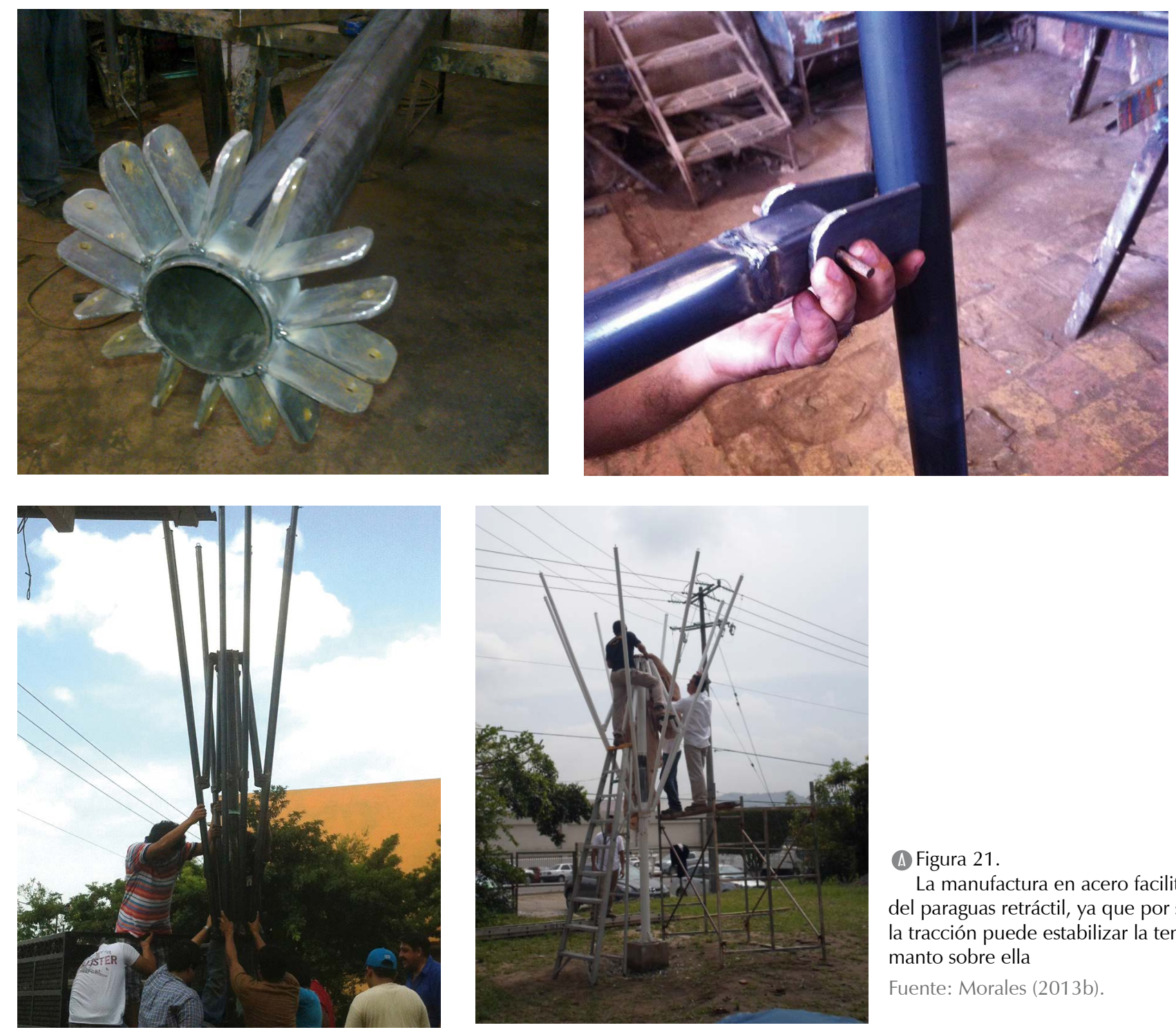

(4) Figura 21.

La manufactura en acero facilitó la construcción del paraguas retráctil, ya que por su alta resistencia a la tracción puede estabilizar la tensión que generará el manto sobre ella

Fuente: Morales (2013b)
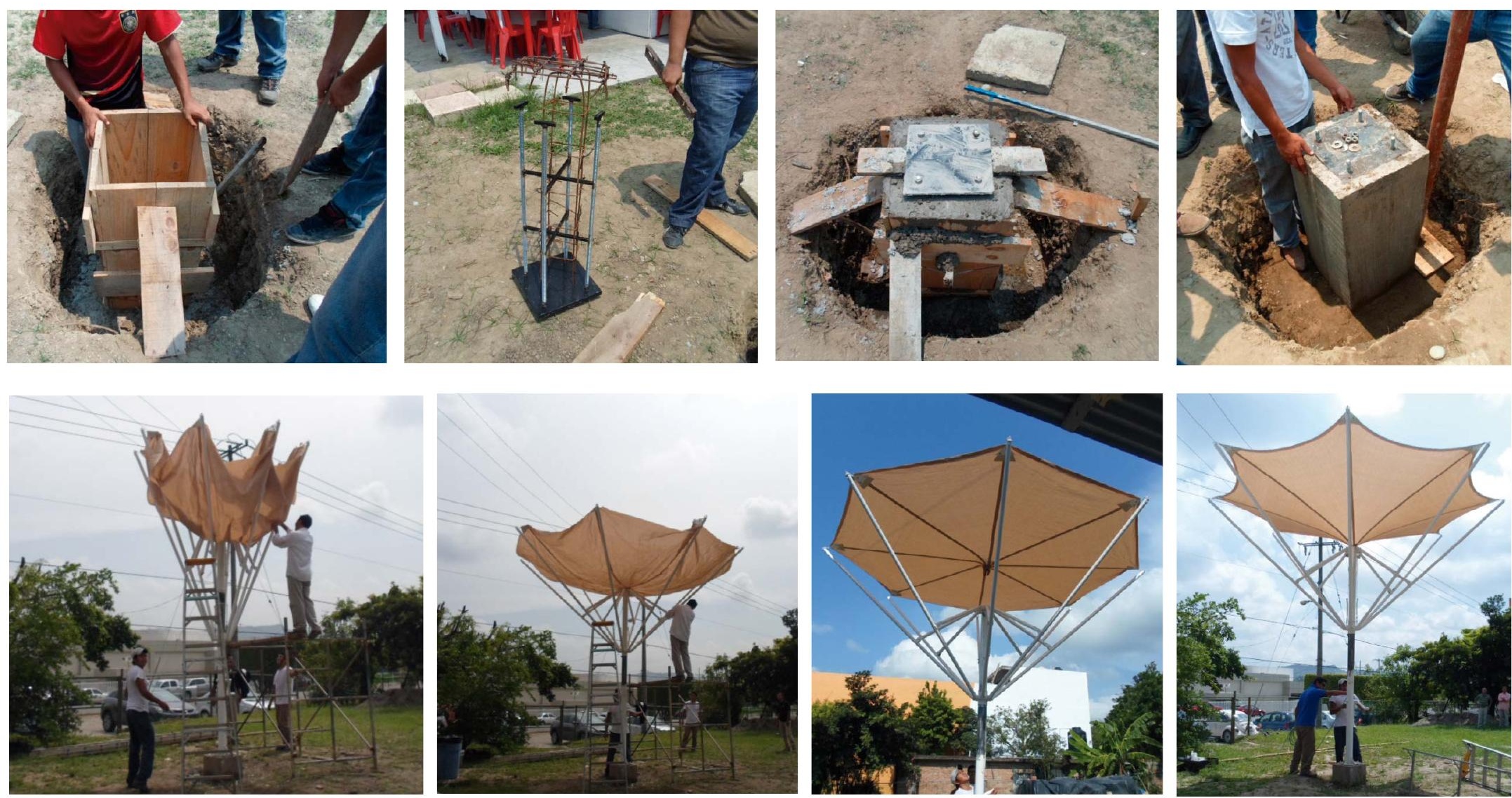

(A) Figura 22. Proceso constructivo del prototipo de paraguas retráctil, desde la cimentación

hasta el montaje, y desplegado de la vela en la estructura, esto se desarrolló en la Facultad de Arquitectura de la Universidad Veracruzana, Campus Poza Rica

Fuente: Morales (2013b). 
al lado que recibirá el poste central; ya en el proceso de montaje se colocó la membrana que tensa el paraguas retráctil y ayuda a rigidizar todo el sistema. En el proceso se tuvieron problemas en el tensado ya que el factor económico afectó a la construcción y se tuvieron que recortar los miembros secundarios de la estructura y la membrana tensada se redujo a un diámetro de $5 \mathrm{~m}$, situación que afectó estéticamente el trabajo final.

\section{CONCLUSIONES}

En el estudio de la tecnología estructural y la industrialización del espacio se realizó la investigación con base en un principio estructural transformable. Esta se maneja como un sistema plegable retráctil, lo que dio como resultado una estructura flexible, adaptable a su contexto, a sus formas, y versátil para cambiar los espacios. El principio de diseño se inclinó a la construcción de un nodo, el cual podía unir dos elementos para crear un sistema estructural muy flexible y resistente.

Toda esta perspectiva conceptual está justificada por las tendencias tecnológicas encontradas en la línea histórica de los sistemas transformables, los cuales nos dejan principios básicos que pueden ayudar a reforzar la metodología de diseño utilizada en este estudio. En la estructura del tiempo se encontraron tres principios básicos que se tomaron como referentes para el diseño de una cubierta plegable, que dieron origen a esta obra: la flexibilidad constructiva encontrada en las tribus beduinas; la prefabricación, como la implementó Emilio Pérez Piñero, y la transformabilidad, como en las construcciones del doctor Felix Escrig, creando íconos de diseño para la investigación.

Así mismo, la investigación teórica sobre las hipótesis encontradas para realizar un sistema transformable fue un factor muy importante para una primera aproximación conceptual, porque sus aportaciones teórico-prácticas se asumen como un principio formal de la metodología de adecuación geométrica que ayudaría a crear las estructuras plegables, generando posibles hipótesis de proceso geométrico que se comparan con propuestas aproximadas de conexiones, para lo cual se requiere abundar más sobre el tema para posibles aportaciones posteriores.

Todo esto deja una propuesta para realizar posteriormente un análisis estructural de estas adecuaciones, las cuales se comparan con la estructura de los referentes; estos sirven para saber el porqué del origen de un método utilizado extrapolando información de distintas normativas constructivas y apoyados en programas informáticos para realizar con más rapidez el análisis estructural de dicho sistema, con esto se teoriza una aproximación de utilización funcional, ya que dichos reglamentos se aplican dependiendo del uso de la estructura; en nuestro caso, lo dejamos abierto a un espacio de tipo industrial, ya que la estructura puede cumplir con otras funciones, gracias a su alternativa plegable.

Las aplicaciones tecnológicas y técnicas del proyecto se vieron reflejadas en la estructura. En la construcción del prototipo se adoptaron alternativas debido a la carencia de herramientas especiales y costo del material, pero el ejecutar el sistema nos ayudó a generar muchos conocimientos, parámetros y premisas para realizar una reconfiguración constructiva de conexiones, y también para considerar la membrana estructural desde un principio, a fin de conocer anticipadamente las tensiones reales que iban a interactuar en el diseño de esta estructura retráctil, así como también tomar en cuenta otras normas y materiales que pudieran mejorar el proceso de la investigación.

\section{REFERENCIAS}

Buckminster Fuller, R. (1963). Nine Chains to the Moon. Carbondale: Southern Illinois University Press.

Morales Guzmán, C. C. (2011). Sistemas de diseño para la vivienda. Revista de Arquitectura, 13(1), 118-127. Recuperado de http://editorial.ucatolica.edu.co/ojsucatolica/revistas ucatolica/index.php/RevArq/ article/view/775

Morales Guzmán, C. C. (2012a). Diseño de sistemas flexibles en el espacio arquitectónico. Madrid: Editorial Academia Española.

Morales Guzmán, C. C. (2012b). Diseño de una cubierta retráctil tensada, Actividad Post Doctoral, Universidad Politécnica de Catalunya.
Morales Guzmán, C. C. (2013a). Informe Técnico: Sistemas Estructurales Retractiles, Universidad Veracruzana.

Morales Guzmán, C. C. (2013b). Prototipo: diseño de una cubierta retráctil tensada. Universidad Veracruzana.

Morales Guzmán, C. C. (2013c). Prototipo de diseño de una cubierta retráctil tensada. Revista de Arquitectura, 15(1), 102-110. doi:http:// dx.doi.org/10.14718/RevArq.2013.15.1.11

Pallares, F. E., Valcarel, J. P. y Escrig, F. (2012). Modular, ligero, transformable: un paseo por la arquitectura ligera móvil. Sevilla: Universidad de Sevilla.
RCDF (Reglamento de Construcción del Distrito Federal). Recuperado de: http://cgservicios. df.gob.mx/prontuario/vigente/385.htm

Rodríguez, N. (2005). Diseño de una estructura transformable por deformación de una malla plana en su aplicación a un refugio de rápido montaje. Barcelona: Universidad Politécnica de Catalunya.

Sastre, R. Wintess (Versión 3.1) [Software computacional] Escuela Técnica Superior de Arquitectura, Universidad Politécnica de Cataluña. 
La postulación de un artículo a la Revista de Arquitectura indica que- el o los autores certifican que conocen y aceptan la política editorial, para lo cual firmarán en original y remitirán el formato RevArq FP00 Carta de originalidad.

La Revista de Arquitectura maneja una política de Autoarchivo VERDE, según las directrices de SHERPA/RoMEO, por lo cual el autor puede:

Pre-print del autor: Archivar la versión pre-print (la versión previa a la revisión por pares)

Post-print del autor: Archivar la versión post-print (la versión final posterior a la revisión por pares)

Versión de editor/PDF: Archivar la versión del editor - PDF/HTML/XLM en la maqueta de la Revista de Arquitectura.

El Autoarchivo se debe hacer respetando la licencia de acceso abierto, la integridad y la imagen de la Revista de Arquitectura, también se recomienda incluir la referencia, el vínculo electrónico y el DOI.

El autor o los autores son los titulares del Copyright (c) del texto publicado y la Editorial de la Revista de Arquitectura solicita la firma de una autorización de reproducción del artículo (RevArq FP03 Autorización reproducción), la cual se acoge a la licencia CC, donde se expresa el derecho de primera publicación de la obra.

La Revista de Arquitectura se guía por las normas internacionales sobre propiedad intelectual y derechos de autor, y de manera particular el artículo 58 de la Constitución Política de Colombia, la Ley 23 de 1982 y el Acuerdo 172 del 30 de septiembre de 2010 (Reglamento de propiedad intelectual de la Universidad Católica de Colombia).

Para efectos de autoría y coautoría de artículos se diferencian dos tipos: "obra en colaboración" y "obra colectiva". La primera es aquella cuya autoría corresponde a todos los participantes al ser fruto de su trabajo conjunto. En este caso, quien actúa como responsable y persona de contacto debe asegurar que quienes firman como autores han revisado y aprobado la versión final, y dan consentimiento para su divulgación. La obra colectiva es aquella en la que, aunque participan diversos colaboradores, hay un autor que toma la iniciativa, la coordinación y realización de dicha obra. En estos casos, la autoría corresponderá a dicha persona (salvo pacto en contrario) y será suficiente únicamente con su autorización de divulgación.

El número de autores por artículo debe estar justificado por el tema, la complejidad y la extensión, y no deberá ser superior a la media de la disciplina, por lo cual se recomienda que no sea mayor de cinco. El orden en que se enuncien corresponderá a los aportes de cada uno a la construcción del texto, se debe evitar la autoría ficticia o regalada. Si se incluyen más personas que trabajaron en la investigación se sugiere que sea en calidad de colaboradores o como parte de los agradecimientos. La Revista de Arquitectura respetará el número y el orden en que figuren en el original remitido. Si los autores consideran necesario, al final del artículo pueden incluir una breve descripción de los aportes individuales de cada uno de firmantes.

La comunicación se establece con uno de los autores, quien a su vez será el responsable de informar a los demás autores de las notificaciones emitidas por la Revista de Arquitectura.

En virtud de mantener el equilibro de las secciones y las mismas oportunidades para todos los participantes, un mismo autor puede postular dos o más artículos de manera simultánea; si la decisión editorial es favorable y los artículos son aceptados, su publicación se realizará en números diferentes.

\section{(A) ACCESO ABIERTO}

La Revista de Arquitectura, en su misión de divulgar la investigación y apoyar el conocimiento y la discusión en los campos de interés, proporciona acceso abierto, inmediato e irrestricto a su contenido de manera gratuita mediante la distribución de ejemplares impresos y digitales. Los interesados pueden leer, descargar, guardar, copiar y distribuir, imprimir, usar, buscar o referenciar el texto completo o parcial de los artículos o la totalidad de la Revista de Arquitectura.

\section{(c) (1) (9)}

Esta revista se acoge a la licencia Creative Commons (CC BYNC de Atribución - No comercial 4.0 Internacional): "Esta licencia permite a otros entremezclar, ajustar y construir a partir de su obra con fines no comerciales, y aunque en sus nuevas creaciones deban reconocerle su autoría y no puedan ser utilizadas de manera comercial, no tienen que estar bajo una licencia con los mismos términos".

La Revista de Arquitectura es divulgada en centros y grupos de investigación, en bibliotecas y universidades, y en las principales facultades de Arquitectura, mediante acceso abierto a la versión digital y suscripción anual al ejemplar impreso o por medio de canje, este último se formaliza mediante el formato RevArq FP20 Canjes.

Para aumentar su visibilidad y el impacto de los artículos, se envían a bases de datos y sistemas de indexación y resumen (SIR) y, asimismo, pueden ser consultados y descargados en la página web de la revista.

La Revista de Arquitectura no maneja cobros, tarifas o tasas de publicación de artículo (Article Processing Charge-APC), o por el sometimiento de textos a la publicación.

\section{(1ÉTICA Y BUENAS PRÁCTICAS}

La Revista de Arquitectura se compromete a cumplir y respetar las normas éticas en todas las etapas del proceso de publicación. Los autores de los artículos publicados darán cumplimiento a los principios éticos contenidos en las diferentes declaraciones y legislaciones sobre propiedad intelectual y derechos de autor específicos del país donde se realizó la investigación. En consecuencia, los autores de los artículos postulados y aceptados para publicar, que presentan resultados de investigación, deben firmar la declaración de originalidad (formato RevArq FP00 Carta de originalidad).

La Revista de Arquitectura reconoce y adopta los principios de transparencia y buenas prácticas descritos por COPE, "Principles of Transparency and Best Practice in Scholarly Publishing" (2015).

El equipo editorial tiene la obligación de guardar la confidencialidad acerca de los artículos recibidos, y abstenerse de usar en sus propias investigaciones datos, argumentos o interpretaciones hasta tanto el artículo no sea publicado. También debe ser imparcial y gestionar los artículos de manera adecuada y en los plazos establecidos. La selección de revisores se hará con objetividad y estos deberán responder a la temática del artículo.

El editor, los autores y los revisores deben seguir las normas éticas internacionales definidas por el Committee on Publication Ethics (COPE), con el fin de evitar casos de:

- Fabricación, falsificación u omisión de datos.

- Plagio y autoplagio.

- Publicación redundante, duplicada o fragmentada.

- Omisión de referencias a las fuentes consultadas.

- Utilización de contenidos sin permiso o sin justificación.

- Apropiación individual de autoría colectiva.

- Cambios de autoría.

- Conflicto de interés (CDI) no revelado o declarado.

- Otras que pudieran surgir en el proceso de investigación y publicación. La fabricación de resultados se genera al mostrar datos inventados por los autores; la falsificación resulta cuando los datos son manipulados y cambiados a capricho de los autores; la omisión se origina cuando los autores ocultan deliberadamente un hecho o dato. El plagio se da cuando un autor presenta como ideas propias datos creados por otros. Los casos de plagio son los siguientes: copia directa de un texto sin entrecomillar o citar la fuente, modificación de algunas palabras del texto, paráfrasis y falta de agradecimientos; el autoplagio se da cuando el mismo autor reutiliza material propio que ya fue publicado, pero sin indicar la referencia al trabajo anterior. La revista se apoya en herramientas digitales que detectan cualquiera de estos casos en los artículos postulados, y es labor de los editores y revisores velar por la originalidad y fidelidad en la citación. La publicación redundante o duplicada se refiere a la copia total, parcial o alterada de un trabajo ya publicado por el mismo autor

En caso de sospechar de alguna mala conducta se recomienda seguir los diagramas de flujo elaborados por COPE (2008), con el fin de determinar las acciones correspondientes.

La Revista de Arquitectura se reserva el derecho de retractación de publicación de aquellos artículos que, posterior a su publicación, se demuestre que presentan errores de buena fe, o cometieron fraudes o malas prácticas científicas. Esta decisión se apoyará en "Retraction Guidelines" (COPE, 2009). Si el error es menor, este se podrá rectificar mediante una nota editorial de corrección o una fe de erratas. Los autores también tienen la posibilidad de solicitar la retractación de publicación cuando descubran que su trabajo presenta errores graves. En todos los casos se conservará la versión electrónica y se harán las advertencias de forma clara e inequívoca.

\section{A PRIVACIDAD Y MANEJO DE LA INFORMACIÓN.} HABEAS DATA

Para dar cumplimiento a lo previsto en el artículo 10 del Decreto 1377 de 2013, reglamentario de la Ley 1581 de 2012, y según el Acuerdo 002 del 4 de septiembre de 2013 de la Universidad Católica de Colombia, "por el cual se aprueba el manual de políticas de tratamiento de datos personales"

La Universidad Católica de Colombia, considerada como responsable o encargada del tratamiento de datos personales, manifiesta que los datos personales de los autores, integrantes de los comités y pares revisores, se encuentran incluidos en nuestras bases de datos; por lo anterior, y en cumplimiento de las disposiciones legales vigentes, la Universidad solicitará siempre su autorización, para que en desarrollo de sus funciones propias como Institución de Educación Superior, en especial las relacionadas con la docencia, la extensión y la investigación, la Universidad Católica de Colombia pueda recolectar, recaudar, almacenar, usar, circular, suprimir, procesar, intercambiar, compilar, dar tratamiento, actualizar, transmitir o transferir a terceros países y disponer de los datos que le han suministrado y que han sido incorporados en las bases de datos de todo tipo que reposan en la Universidad.

La Universidad Católica de Colombia queda autorizada, de manera expresa e inequívoca, en los términos señalados por el Decreto 1377 de 2013, para mantener y manejar la información de nuestros colaboradores (autores, integrantes de los diferentes comités y pares revisores); así mismo, los colaboradores podrán ejercer sus derechos a conocer, actualizar, rectificar y suprimir sus datos personales, para lo cual se han dispuesto las siguientes cuentas de correo electrónico: 
La Revista de Arquitectura recibe artículos de manera permanente. Los artículos se procesan a medida que se postulan, dependiendo el flujo editorial de cada sección.

El idioma principal es el español, y como opcionales están definidos el inglés, el portugués y el francés; los textos pueden ser escritos y presentados en cualquiera de estos.

Los artículos postulados deben corresponder a las categorías universalmente aceptadas como producto de investigación, ser originales e inéditos y sus contenidos responder a criterios de precisión, claridad y brevedad.

Como punto de referencia se pueden tomar las tipologías y definiciones del Índice Bibliográfico Nacional, Publindex (2010) que se describen la continuación:

1. Artículo de revisión: documento resultado de una investigación terminada donde se analizan, sistematizan e integran los resultados de investigaciones publicadas o no publicadas, sobre un campo en ciencia o tecnología, con el fin de dar cuenta de los avances y las tendencias de desarrollo. Se caracteriza por presentar una cuidadosa revisión

bibliográfica de por lo menos 50 referencias.
2. Artículo de investigación científica y tecnológica: documento que presenta, de manera detallada, los resultados originales de proyectos terminados de investigación. La estructura generalmente utilizada contiene cuatro apartes importantes: introducción, metodología, resultados y conclusiones.

3. Artículo de reflexión: documento que presenta resultados de investigación terminada desde una perspectiva analítica, interpretativa o crítica del autor, sobre un tema específico, recurriendo a fuentes originales.

En todos los casos se debe presentar la información suficiente para que cualquier investigador pueda reproducir la investigación y confirmar o refutar las interpretaciones defendidas.

También se pueden presentar otro tipo de documentos diferentes a los anteriormente descritos, como pueden ser: artículo corto, reporte de caso, revisión de tema, documento resultado de la revisión crítica de la literatura sobre un tema en particular, cartas al editor, traducción, documento de reflexión no derivado de investigación, reseña bibliográfica, así como proyectos de arquitectura o urbanismo, entre otros

\section{A INSTRUCCIONES PARA POSTULAR ARTÍCULOS}

Postular el artículo en la página web de la Revista de Arquitectura y adjuntar comunicación escrita dirigida al editor RevArq_FP00 Carta de originalidad (debidamente firmada por todos los autores en original); de igual manera, se debe diligenciar el formato de hoja de vida RevArq FP01 Hoja de Vida (una por cada autor).

En la comunicación escrita el autor expresa que conoce y acepta la política editorial de la Revista de Arquitectura, que el artículo no está postulado para publicación simultáneamente en otras revistas u órganos editoriales y que no existe conflicto de intereses (ver modelo RevArq FP06 CDI) y que, de ser aceptado, concederá permiso de primera publicación, no exclusiva a nombre de la Universidad Católica de Colombia como editora de la revista.

Los artículos deben tener en cuenta las siguientes recomendaciones:

- En la primera página del documento se debe incluir:

TítUlo: no exceder 15 palabras.

Subtítulo: opcional, complementa el título o indica las principales subdivisiones del texto.

NOMBRE DEL AUTOR O AUTORES: nombres y apellidos completos o según modelo de citación adoptado por el autor para la normalización de los nombres del investigador. Como nota al pie (máximo 150 palabras): formación académica, experiencia profesional e investigativa, vinculación laboral, premios o reconocimientos, publicaciones representativas e información de contacto, correo electrónico.

FILIACIÓN INSTITUCIONAL: debajo del nombre se debe declarar la inV titución en la cual se desarrolló el producto, de la cual recibió apoyo o aquella que respalda el trabajo investigativo.

RESUMEN: debe ser analítico, se redacta en un solo párrafo, da cuenta del tema, el objetivo, la metodología, los resultados y las conclusiones; no debe exceder las 150 palabras.

PALABRAS CLAVE: cinco palabras o grupo de palabras, ordenadas alfabéticamente y que no se encuentren en el título o subtítulo; estas sirven para clasificar temáticamente al artículo. Se recomienda emplear principalmente palabras definidas en el tesauro de la Unesco (http:// databases.unesco.org/thessp/) o en el tesauro de Arte \& Arquitectura (C) (www.aatespanol.cl).

También se recomienda incluir título, resumen y palabras clave en segundo idioma.

- La segunda página y siguientes deben tener en cuenta:

El cuerpo del artículo generalmente se divide en: Introducción, Metodología, Desarrollo, Resultados y Discusión de resultados; posteriormente se presentan las Conclusiones, y luego las Referencias bibliográficas y los Anexos (método IMRYD). Las tablas y figuras se deben incorporar en el texto.

DESCRIPCIÓN DEL PROYECTO DE INVESTIGACIÓN: en la introducción se debe describir el tipo de artículo y brevemente el marco investigativo del cual es resultado y diligenciar el formato (RevArq FP02 Info Proyectos de Investigación).

TEXTO: todas las páginas deben venir numeradas y con el título de artículo en la parte inferior (pie de página). Márgenes de $3 \mathrm{~cm}$ por todos los lados, interlineado doble, fuente Arial o Times New Roman de 12 puntos, texto justificado (Ver plantilla para presentación de artículos). La extensión de los artículos debe ser de alrededor de 5.000 palabras ( \pm 20 páginas, incluyendo gráficos, tablas, referencias, etc.); como mínimo 3.500 y máximo 8.000 palabras. Se debe seguir el estilo vigente y recomendado en el Manual para Publicación de la American Psychological Association (APA). (Para mayor información véase http://www.apastyle.org/)
CITAS Y NOTAS AL PIE: las notas aclaratorias o notas al pie no deben exceder cinco líneas o 40 palabras, de lo contrario estas deben ser incorporadas al texto general. Las citas pueden ser:

Corta: (con menos de 40 palabras) se incorporan al texto y pueden ser: textuales (se encierran entre dobles comillas), parafraseo o resumen (se escriben en palabras del autor dentro del texto).

Cita textual extensa: (mayor de 40 palabras) debe ser dispuesta en un renglón y un bloque independiente con sangrías y omitiendo las comillas, no olvidar en ningún caso la referencia del autor (Apellido, año, página).

REFERENCIAS: como modelo para la construcción de referencias se emplea el estilo recomendado en el Manual para Publicación de la American Psychological Association (APA) (http://www.apastyle.org/).

SIGLAS: en caso de emplear siglas en el texto, las figuras o las tablas, se debe proporcionar la equivalencia completa la primera vez que se empleen y encerrarlas entre paréntesis. En el caso de citar personajes reconocidos se deben colocar nombres o apellidos completos, nunca emplear abreviaturas.

GRÁFICOS Y TABLAS: las figuras (gráficos, diagramas, ilustraciones, planos, mapas o fotografías) y las tablas deben ir numeradas y contene título o leyenda explicativa relacionada con el tema del artículo, que no exceda las 15 palabras (Figura 1. xxxxx, Tabla 1. xxxx, etc.) y la procedencia (fuente: autor o fuente, año, página). Estas se deben citar en e texto de forma directa o entre paréntesis; se recomienda hacerlo con referencias cruzadas.

También se deben entregar en medio digital, independiente del texto, en formatos editables o abiertos. La marcación de los archivos debe corresponder a la incluida en el texto. Según la extensión del artículo se deben incluir de 5 a 10 gráficos. Ver guía para la búsqueda de imágenes de dominio público o bajo licencias Creative Commons (CC).

El autor es el responsable de adquirir los derechos o las autorizaciones de reproducción a que haya lugar para imágenes o gráficos tomados de otras fuentes, así como de entrevistas o material generado por colaboradores diferentes a los autores; de igual manera, se debe garantizar la protección de datos e identidades para los casos que sea necesario.

FOTOGRAFíA: pueden ser entregadas en original para ser digitalizadas, de lo contrario se deben digitalizar con una resolución igual o superior a 300 dpi para imágenes a color y 600 para escala de grises. Los formatos de las imágenes pueden ser TIFF, PSD o JPG, y deben cumplir con las características expresadas en el punto anterior (gráficos).

PLANIMETRÍA: se debe entregar la planimetría original en medio digital en lo posible en formato CAD, y sus respectivos archivos de plumas o en PDF; de no ser posible, se deben hacer impresiones en tamaño carta con las referencias de los espacios mediante numeración y lista adjunta. Deben tener escala gráfica, escala numérica, norte, coordenadas y localización. En lo posible, no deben contener textos, achurados o tramas.

Para más detalles, consultar el documento RevArq Parámetros para Autores Descripción en el portal web de la Revista de Arquitectura

\section{Beneficios}

Como reconocimiento a los autores, se les hará envío postal de dos ejemplares de la edición impresa sin ningún costo y entregada en la dirección consignada en el formato de hoja de vida (RevArq FP01); adicionalmente, se enviará el vínculo para la descarga de la versión digital.

También se enviará una constancia informativa en la que se relaciona la publicación del artículo y, de manera opcional, se pueden detallar las fechas del proceso editorial y el arbitraje realizado. 
La selección de revisores se realiza de acuerdo con los siguientes criterios:

- Afinidad temática.

- Formación académica.

- Experiencia investigativa y profesional.

- Producción editorial en revistas similares o en libros resultado de investigación.

El proceso de arbitraje se basa en los principios de equidad e imparcialidad, y en los criterios de calidad y pertinencia.

El desarrollo de la revisión se realiza según el formato (RevArq FP10 Evaluación de artículos) y las observaciones que el revisor considere necesarias en el cuerpo del artículo. En cualquiera de los conceptos que emita el revisor (Aceptar, Publicable con modificaciones, Reevaluable o No publicable), y como parte de la labor formativa y de comunidad académica, el revisor hará sugerencias para mejorar el documento. El revisor podrá solicitar una nueva relectura del artículo después de los ajustes realizados por el autor.

El revisor también deberá diligenciar el formato RevArq FP01 Hoja de Vida, con el fin de certificar y soportar el proceso de revisión ante los SIR que así lo soliciten.

En el proceso de arbitraje se emplea el método doble ciego, los nombres del revisor no serán conocidos por el autor y viceversa. Con el fin de garantizar el anonimato del autor, al artículo postulado se le han podido suprimir nombres, instituciones o imágenes que puedan ser asociadas de manera directa al autor.

Aunque se procura el anonimato, una vez recibida la invitación como par revisor del artículo, el revisor debe cerciorarse de que no exista conflicto de intereses (CDI) o alguna limitante que afecte la revisión o que pueda ser vista como tal (lazos familiares, amistad o enemistad, vínculos contractuales o laborales, posiciones éticas, etc.), de presentarse esta situación se notificara al editor. (Ver modelo RevArq FP06 CDI).

Dada la confidencialidad del proceso de revisión, y considerando los derechos de autor y de propiedad intelectual que pueda haber sobre el material que se entrega, el revisor se compromete a mantener en absoluta reserva su labor, a limitar el uso de la obra entregada solo para el propósito designado y a devolver la documentación remitida una vez concluya la actividad.

El tiempo establecido para las revisiones de pares es de máximo un mes a partir de la confirmación de la recepción de la documentación. Ese plazo podrá ser modificado de mutuo acuerdo entre el editor y el revisor, siempre y cuando no afecte la periodicidad de la revista, la impresión o el tiempo para emitir una respuesta al autor. Los revisores se acogerán a "COPE Ethical Guidelines for Peer Reviewers" de COPE.

\section{Beneficios}

Como retribución a los revisores se les hará envío postal de un ejemplar de la edición impresa sin ningún costo y entregada en la dirección consignada en el formato de hoja de vida. También, si es de interés para el revisor, podrá hacer la solicitud de alguna de las publicaciones editadas y presentes en el catálogo de publicaciones de la UNIVERSIDAD Católica de Colombia, previa aprobación de la Editorial y sujeto a la disponibilidad.

Si lo desea tendrá derecho a una constancia de la colaboración en la revisión de artículos, la cual solo contendrá el periodo en el cual se realizó la actividad. También tendrá la posibilidad de aceptar o no la publicación de su nombre, nacionalidad y nivel máximo de formación en la página web de la Revista de Arquitectura en su calidad de colaborador.

\section{(A) PROCESO DE REVISIÓN POR PARES}

Luego de la postulación del artículo, el editor de la Revista de Arquitectura selecciona y clasifica los artículos que cumplen con los requisitos establecidos en las directrices para los autores. El editor podrá rechazar en primera instancia artículos, sin recurrir a un proceso de revisión, si los considera de baja calidad o por presentar evidencias de faltas éticas o documentación incompleta.

Los artículos se someterán a un primer dictamen del editor, de los editores de sección y del Comité Editorial, teniendo en cuenta:

- Afinidad temática, relevancia del tema y correspondencia con las secciones definidas.

- Respaldo investigativo.

- Coherencia en el desarrollo del artículo, así como una correcta redacción y ortografía.
- Relación entre las figuras y tablas con el texto del artículo.

En esta revisión se verificará el nivel de originalidad mediante el uso de software especializado (Ithenticate o similar) y recursos digitales existentes para tal fin, también se observará la coherencia y claridad en los apartados del documento (método IMRYD), la calidad de las fuentes y la adecuada citación, esto quedará consignado en el formato (RevArq FP09 Revisión de artículos); esta información será cargada a la plataforma de gestión editorial y estará a disposición del autor.

En caso de que el artículo requiera ajustes preliminares, será devuelto al autor antes de ser remitido a revisores. En este caso, el autor tendrá veinte días para remitir nuevamente el texto con los ajustes solicitados.

Después de la preselección se asignan mínimo dos revisores especializados, quienes emitirán su concepto utilizando el formato (RevArq FP10 Evaluación de artículos) y las anotaciones que consideren oportunas en el texto; en esta etapa se garantizará la confidencialidad y el anonimato de autores y revisores (modalidad doble ciego).

Del proceso de revisión se emite uno de los siguientes conceptos que será reportado al autor:

- Aceptar el envío: con o sin observaciones.

- Publicable con modificaciones: se podrá sugerir la forma más adecuada para una nueva presentación, el autor puede o no aceptar las observaciones según sus argumentos. Si las acepta, cuenta con quince días para realizar los ajustes pertinentes.

- Reevaluable: cumple con algunos criterios y debe ser corregido. Es necesario hacer modificaciones puntuales y estructurales al artículo. En este caso, el revisor puede aceptar o rechazar hacer una nueva lectura del artículo luego de ajustado.

- No publicable: el autor puede volver a postular el artículo e iniciar nuevamente el proceso de arbitraje, siempre y cuando se evidencien los ajustes correspondientes.

En el caso de presentarse diferencias sustanciales y contradictorias en los conceptos sobre la recomendación del revisor, el editor remitirá el artículo a un revisor más o a un miembro del Comité Editorial quien podrá actuar como tercer árbitro, con el fin de tomar una decisión editorial sobre la publicación del artículo.

Los autores deberán considerar las observaciones de los revisores o de los editores, y cada corrección incorporada u omitida debe quedar justificada en el texto o en una comunicación adjunta. En el caso que los autores omitan las indicaciones realizadas sin una argumentación adecuada, el artículo será devuelto y no se dará por recibido hasta que no exista claridad al respecto.

El editor respetará la independencia intelectual de los autores y a estos se les brindará el derecho de réplica en caso de que los artículos hayan sido evaluados negativamente y rechazados.

Los autores, con su usuario y contraseña, podrán ingresar a la plataforma de Gestión Editorial, donde encontrarán los conceptos emitidos y la decisión editorial sobre el artículo.

El editor y el Comité Editorial se reservan el derecho de aceptar o no la publicación del material recibido. También se reservan el derecho de sugerir modificaciones de forma, ajustar las palabras clave o el resumen y de realizar la corrección de estilo. El autor conocerá la versión final del texto antes de la publicación oficial del mismo.

Cuando un artículo es aceptado para su publicación, el auto debe firmar la autorización de reproducción (RevArq FP03 Autorización reproducción). Para más información ver: Política de derechos de autor

\section{Notas aclaratorias:}

La Revista de Arquitectura publica un número limitado de artículos por volumen y busca el equilibrio entre las secciones, motivo por el cual, aunque un artículo sea aceptado o continúe en proceso de revisión, podrá quedar aplazado para ser publicado en un próximo número; en este caso, el autor estará en la posibilidad de retirar la postulación del artículo o de incluirlo en el banco de artículos del próximo número.

El editor y los editores de sección de la Revista de Arquitectura son los encargados de establecer contacto entre los autores y revisores, ya que estos procesos se realizan de manera anónima.

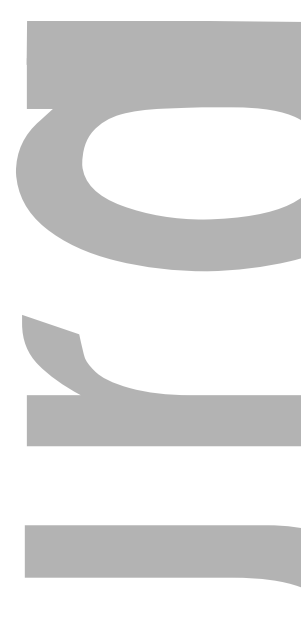

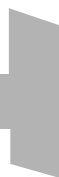
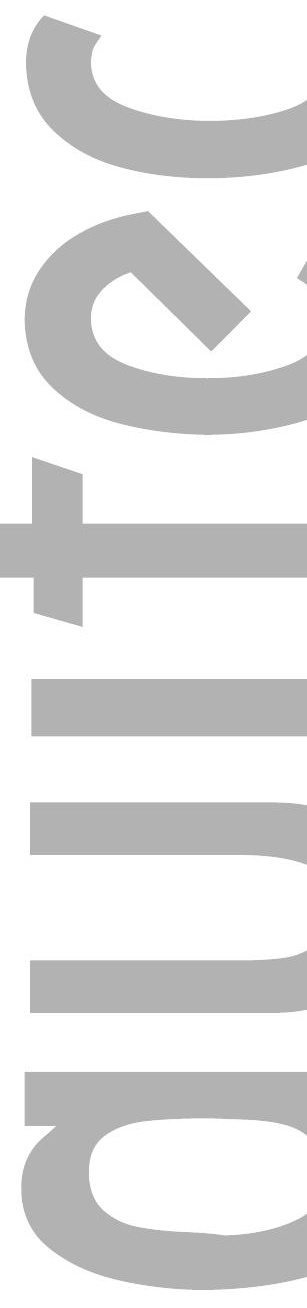

(2)

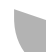

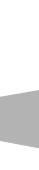

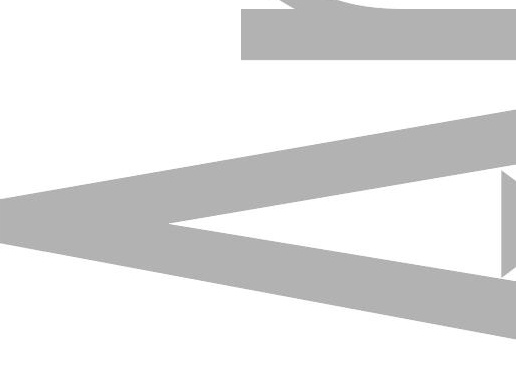


THE SOCIAL REPRESENTATION OF PUBLIC SPACE FOR THE DESIGN AND

MANAGEMENT OF SUSTAINABLE TERRITORIES

A THEORETICAL-PRACTICAL AND METHODOLOGICAL PROPOSAL FOR

PARTICIPATORY PLANNING

\section{Heidi Natalie Contreras-Lovich}

\section{PROPUESTA DE UN SISTEMA DE INDICADORES PARA EVALUAR}

PROPOSAL FOR A SYSTEM OF INDICATORS TO ASSESS THE VISUAL QUALITY OF

THE URBAN LANDSCAPE IN INFORMAL SETTLEMENTS

Johana Andrea Mesa Carranza, OsWaldo López Bernal.

Adriana Patricia López Valencia

Segregación EN EL ESPACIO URBANO de SOACHA

¿TRANSMILENIO COMO HERRAMIENTA INTEGRADORA?

SEGREGATION IN THE URBAN SPACE OF SOACHA

TRANSMILENIO AS AN INTEGRATING TOOL?

CARLos Augusto Moreno-Luna

\section{AROUITETURA E INDUSTRIALIZAÇÃO DAS CONSTRUÇÕES NA}

obra de JoÃo Filgueiras LIMA — LELÉ

ARCHITECTURE AND CONSTRUCTION'S INDUSTRIALIZATION IN THE WORK OF

JoĀo FilgueIrAs LIMA - LELÉ

Elza-Luli Miyasaka, Marieli Lukiantchuki, Michele C. B. Ferrari

CAIXETA, Marcio-Minto Fabricio

\section{EL DISEÑO DE LA VIVIENDA DE INTERÉS SOCIAL}

LA SATISFACCIÓN DE LAS NECESIDADES Y EXPECTATIVAS DEL USUARIO

THE DESIGN OF SOCIAL HOUSING

MEETING THE NEEDS AND USER EXPECTATIONS

Alex Leandro Pérez-PÉrez

EXPLORACIONES MORFOLÓGICAS EN TEXTURAS MODULARES

APROXIMACIONES DESDE EL OBJET TROUVÉ AL DISEÑO

نं PARAMÉTRICO

MORPHOLOGICAL EXPLORATIONS IN MODULAR TEXTURES

APPROXIMATIONS FROM OBJET TROUVÉ TO THE PARAMETRIC DESIGN

\section{CONSTRUCCIÓN EXPERIMENTAL DE UN SISTEMA}

